\title{
When Enough Is Not Enough: \\ Structural Credit Risk Based Estimation of Bank Capital*
}

\author{
Michael B. Imerman \\ Princeton University
}

First Version: October 2010

This Version: September 2011

JEL Classification: G01, G21, G28, G32

\footnotetext{
* Department of Operations Research \& Financial Engineering, Princeton University, Princeton, NJ 08544. Email: mimerman@princeton.edu; Phone: (609) 258-1889. An earlier version of this paper was circulated under the title "Dynamic Bank Capital: A Structural Credit Risk Approach" and is based on Chapter 2 of my doctoral dissertation at Rutgers University. I would like to thank my dissertation committee members - Ren-Raw Chen (co-chair), Ben Sopranzetti (co-chair), C.F. Lee, Joe Mason, Darius Palia, and Larry Shepp - for their advice and guidance. I am also grateful for helpful comments and suggestions provided by seminar participants at Rutgers Business School, James Madison University, Oklahoma State University, Villanova University, and State Street Corporation. This paper could not have been completed without the support of the Whitcomb Center for Research in Financial Services at Rutgers Business School.
} 


\title{
When Enough Is Not Enough: Structural Credit Risk Based Estimation of Bank Capital
}

\begin{abstract}
This paper proposes the use of a structural credit risk model to analyze the economic capital of banks. The particular model used in this paper is unique in that it has both endogenous default and a more robust depiction of the liability structure. As a result, it represents a reasonable model for identifying distress in the financial sector. The model yields several useful metrics for evaluating the solvency and economic capital of financial institutions. Contrary to static measures of capital adequacy such as a fixed percentage of assets, which do not capture the true condition of a financial institution, the model is forward-looking in nature and can be used in a dynamic capacity to monitor and estimate the capital needs for banks. Empirical results show that, although the largest US Bank Holding Companies were well capitalized by regulatory standards, there was a dearth of economic capital as the Financial Crisis unfolded in 2008. The implication is that capital levels should be time-varying and conditional upon the health of the particular bank and the financial system as a whole.
\end{abstract}




\section{Introduction}

Despite what we hear about the credit crisis and the problems facing banks, the fact is that the bulk of the U.S. banking industry is healthy and remains well-capitalized.

FDIC Chairman, Sheila Bair, October 14, $2008^{1}$

In the wake of the devastating Financial Crisis of 2007 - 2009, capital requirements, a key regulatory and risk management tool for financial institutions, have once again come into question. A bank's capital is supposed to serve as a buffer against losses and thereby reduce the probability of financial distress and default. When asset values fall, the bank's capital absorbs the losses so that the more senior claimants (i.e. depositors and other creditors) are not impaired significantly. Thus, the solvency of any given bank relies in part on the capital position of the institution. In addition, the soundness of the financial system as a whole depends on the ability of individual banks to withstand market-wide and macroeconomic shocks. Regulators require financial institutions to maintain a certain level of risk-based capital ("regulatory capital") where the capital ratio is computed as a percentage of risk-adjusted assets; thereby, in theory, the riskier the bank's assets the more capital that must be held against those assets. On the other hand, there is "economic capital" which can be thought of as the bank's own assessment of capital needs given the likelihood of future losses on assets. In that respect, the amount of capital needed at a given point in time should reflect the present value of the expected future losses.

In light of regulators' and bank executives' claims that financial institutions were "well capitalized" throughout the recent Financial Crisis, it is clear that something went wrong. This paper will show that the largest bank holding companies (BHCs) in the United States were well capitalized by regulatory standards, but severely undercapitalized in terms of the level of economic capital that should have been held considering the rapidly deteriorating market environment. A structural credit risk

\footnotetext{
${ }^{1}$ http://www.fdic.gov/news/news/press/2008/pr08100a.html
} 
model is presented as a novel approach to estimate implied market-value capital ratios and solve for a financial institution's endogenous capital needs.

The data indicate that risk-based capital ratios do not change much over time, and can be misleading about the true condition of a distressed bank or the financial system in times of crisis. Any indications of trouble often appear too late, leaving regulators and bank managers with limited alternatives. This can be attributed to the fact that traditional measures of bank capital adequacy are static in nature and are the result of historical analysis of the institution's balance sheet and operations. Furthermore, they only account for asset risk. Regulators and policy makers have recognized the shortcomings and are working on devising new methods to address them (see Basel III). However, investors and risk managers must concern themselves not so much with the regulatory capital but rather on how much economic capital is enough. The existing metrics for economic capital rely on VaR and RAROC, which are antiquated at best and also rely on flawed assumptions. Furthermore, data on these metrics for individual financial institutions are not readily available to outsiders.

This paper uses a structural credit risk model to analyze the economic capital of financial institutions both before and during the Financial Crisis. The model uses market data as a key input and provides insights that are consistent with many of the concerns that scholars and experts have identified in the wake of the Financial Crisis. Specifically, the model suggests that an increased reliance on short-term funding should demand higher levels of capital and that capital requirements should be timevarying.

The structural credit risk model is used to first compute default probabilities which serves as the key metric in evaluating the economic capital of the bank in question. When default probabilities become too high or increase at too fast of a rate, it can be viewed as a market signal that there is distress in the individual bank or in the financial system as a whole. The bank's management can then take the necessary steps to ensure that the level of economic capital is adequate enough to withstand expected future losses arising from shocks to asset values. The model can also be 
used as an analytical tool to find the minimum amount of capital that is needed to keep the probability of default within an acceptable range.

The model is essentially a dynamic implementation of the Geske compound option model (see Geske (1977), Geske (1979), Geske and Johnson (1984)). Structural credit risk models, based on the seminal work of Black and Scholes (1973) and Merton (1974), model corporate securities as contingent claims on the firm's assets and can therefore be used to compute default probabilities in terms of the distributional properties of the underlying asset value (as a first passage density or exercise probability) and the nature of the contingent claims' payoffs (boundary conditions). Unfortunately, structural credit risk models have seen little success in analyzing financial institutions, attributable in part to the assumption of an exogenous default boundary and/or oversimplifying the liability structure. In contrast, the approach used in this paper explicitly incorporates information about the seniority and maturity structure of bank liabilities and, furthermore, has an endogenous default condition that provides tremendous insight into the financial institution's ability to recapitalize.

The complex liability structure associated with financial institutions lends itself nicely to the compound option structural credit risk model. A compound option is an option on an option, i.e. the underlying asset is itself an option. This comes directly from the original insight of Black and Scholes (1973) and Merton (1974) who demonstrated that shareholders' decision of whether or not to make a principal payment on risky debt is analogous to the exercise decision on a long call option. When there are multiple cash flows (coupon payments, different classes of debt, etc.) this is best modeled by a compound option as shown by Geske (1977). For example, when a firm has coupon bonds outstanding, each decision to make a payment is contingent on having made the last. The option to make today's coupon payment is conditional on having exercised last period's option. Defaulting on a coupon payment is therefore like allowing the compound option to expire.

Alternatively, Geske (1977) and Geske and Johnson (1984) show how the compound option model can be applied to institutions with subordinated debt in the capital structure. When there are just two classes of debt (short-term and long-term, 
junior and senior), the solution is known in closed-form and can be calculated analytically. $^{2}$ Fortunately, this specification captures the general capital structure of a typical bank quite nicely (this point is expanded upon below), and therefore allows for the explicit calculation of short-term and long-term default probabilities as well as comparative statics.

In addition to the liability structure, the model uses the market value of the assets and the asset volatility as primary inputs. However, since the true asset value and volatility are unobservable, equity market information can be used to solve for these quantities. It should be noted that using equity market information to help gauge the value and quality of bank assets, which tend to be rather "opaque", is common practice in the literature (see Flannery, Kwan, and Nimalendran (2004)). There is a wide body of literature that studies the ability of market participants to assess bank performance and discipline poorly managed banks. ${ }^{3}$ If investors are not pleased with the performance of a particular bank they can sell their information-sensitive claims on the bank (i.e. equity and subordinated debt) thereby driving prices down and the resulting cost of capital up, or in extreme situations even take over the bank or force liquidation. In fact, market discipline has been discussed in the literature as a possible alternative or complementary means of monitoring banks and enforcing bank behavior. ${ }^{4}$ Krainer and Lopez (2004) specifically advocate the use of equity market information in the monitoring of financial institutions.

The structural credit risk model in this paper uses equity market information in the following way. Given the market value of a financial institution's equity and the equity volatility, two equations must be solved in two unknowns to simultaneously obtain measures of the implied asset value and asset volatility. The model outputs include short-term and long-term default probabilities, as well as the total survival probability. The real insight, however, comes from examining the relation-

\footnotetext{
${ }^{2}$ This is as opposed to higher-dimensional compound options where the solution can be written out in "quasi-closed- form" but must be solved numerically.

${ }^{3}$ See, for example, Avery, Belton, and Goldberg (1988), Gorton and Santomero (1990), and Flannery and Sorescu (1996).

${ }^{4}$ See studies by Berger, Davies, and Flannery (2000), Bliss and Flannery (2002), and the survey paper by Flannery (1998).
} 
ship between default probabilities and the minimum level of capital needed to reduce default probabilities for distressed financial institutions. The model is, therefore, a liability-driven approach for analyzing bank capital using market information; this is in stark contrast to the currently employed, static, asset-driven approaches used for both regulatory and economic capital.

Considering the hundreds of billions of dollars that were injected into struggling financial institutions, the recent financial crisis gives rise to an abundance of opportunities for empirically testing the model. The model is used to examine the capital positions for top 15 bank holding companies (BHC's), in terms of average assets, on a quarterly basis over a four year period (2005:Q1 to 2008:Q4) using data from Federal Reserve reports and the equity markets. First, model-implied market value capital ratios are computed and then compared to core capital ratios as defined by the existing risk-based capital regulatory specifications. The core capital ratios are calculated using balance sheet information and static risk weightings; therefore, they should be fairly constant over the sample period. If anything, one might even expect that they rise over the sample period as bank executives attempted to reassure the public that their institution was solvent. On the other hand, the model clearly shows that BHC default probabilities increase over the course of 2008. The source of this pattern comes from increasing volatility, decreasing asset values, and leverage ratios that remained high. It is not surprising to find that the model-implied market value capital ratios decrease over the sample period, and do so at an increasing rate. An additional interesting observation is that market value capital ratios tend to move in opposite directions of core capital ratios.

Next, the model is used to estimate the amount of additional capital that would have been needed to lower default probabilities to a more acceptable level. By the third quarter of 2008, default probabilities were significantly elevated for all 15 BHCs in the sample. It is no coincidence that this was the point where the financial crisis took a turn for the worse. Between September and October of 2008 Fannie Mae and Freddie Mac were placed into federal conservatorship, Lehman Brothers declared bankruptcy, the Federal Reserve Bank of New York propped up AIG, and the govern- 
ment committed $\$ 700$ billion of capital to "bail out" the U.S. financial system through the Troubled Asset Relief Program (TARP). In fact, this provides for a very interesting natural experiment: the amount of economic capital computed by the model are compared to the initial TARP allocations made from October 2008 through December 31,2008 . The results obtained by the model indicate that the capital infusions provided by the TARP program were substantially lower than needed in all but one of the BHCs. It is conceivable that the paucity of capital in the banking system can help explain why conditions continued to deteriorate before they got better from 2008 into 2009. Also, the estimates of the Federal Reserve's Supervisory Capital Assessment Program (the SCAP, better known as the "stress tests") are then incorporated into the analysis to see how the forecasted capital needs, as computed by the regulators, compare to the figures obtained from the model.

The remainder of the paper is structured as follows. The next section, Section 2, reviews the relevant literature, specifically looking at capital adequacy and market discipline in banking. After a brief review of previous structural credit risk models, Section 3 develops a structural model of the banking firm, derives the default probabilities, and proposes the dynamic implementation of the model as well as the application to capital requirements. Section 4 goes through the data and methodology. The empirical results are presented in Section 5 and Section 6 concludes.

\section{Related Literature and Theoretical Background}

The role of bank capital and the importance of developing good capital adequacy standards have been studied extensively in the literature. ${ }^{5}$ This paper deals with how much economic capital a financial institution should have, given market conditions. Diamond and Rajan (2000) show how capital can arise endogenously in a traditional model of financial intermediation. When there is uncertainty, the bank may choose to finance its operations in part with a contract that gives the holder a residual claim to the assets and the cash-flows they produce. The most natural interpretation of

\footnotetext{
${ }^{5}$ For a comprehensive review of the bank capital regulation literature see Santos (2001).
} 
such a claim is as capital, which acts as a protective cushion against shocks to asset values, and in turn makes the bank safer. The downside, however, is that capital reduces liquidity, and one of the primary functions of a bank is its ability to create liquidity. The Diamond and Rajan (2000) model serves to formalize what has served as the conventional wisdom for years: that banks must have some capital to remain solvent, but this capital comes at a cost. Regulatory requirements mandate that banks hold a fixed percentage of risk-weighted assets as capital. However, the definition of capital varies between "Tier 1" and "Tier 2" capital, and may include various hybrid instruments (trust preferred securities, etc.). ${ }^{6}$ However, in its purest form, "capital" refers to common equity.

A fundamental flaw in the risk-based regulatory capital approach is that risk is only taken into account by way of the assets on the balance sheet. ${ }^{7}$ Leverage, and consequently the bank's own default risk, does not play a role in determining how much capital the bank should set aside. All that matters are the asset composition and the relative safety of the asset classes. Exactly how the risk is quantified is also an issue. Some have called for the use of ratings determined by bank's own internal models (see Hendricks and Hirtle (1997)). However, Internal Ratings Based (IRB) capital requirements have been criticized on many grounds, including that it may increase procyclicality in the financial system and exacerbate business cycles (see Kashyap and Stein (2004)); but there is also evidence that using agency ratings results in the same problem (see Altman and Saunders (2001)). Also, banks' reliance on Value-at-Risk (VaR) as the primary risk metric is problematic (these problems also arise with economic capital; a point which will be returned to shortly). The use of VaR in determining risk-based capital requirements was strongly objected by Jarrow (2007).

\footnotetext{
${ }^{6}$ Basel III has taken steps to remove the ambiguity out of the definition of capital; see Basel Committee on Banking Supervision (2011).

${ }^{7}$ Risk-weighted assets, which serve as the denominator of risk-based capital ratios, are determined by multiplying the value in a given asset class by the appropriate risk-weighting (see, for instance, Chapter 20 in Bessis (2010)).
} 
Banks have more freedom in how they determine the amount of economic capital on hand. Economic capital is supposed to represent the present value of expected losses, thereby serving as a reserve or buffer against deterioration in asset value. Economic capital is important internally in banks for other reasons. Typically it can be used for capital allocation, or determining what proportion of the limited resources should be made available to which business units, as well as risk-adjusted performance measures. ${ }^{8}$

A model for determining the appropriate level of economic capital should also be a function of the bank's risk. The predominant metric of bank risk is still the Value-at-Risk or VaR. VaR can be defined as the projected maximum loss that will be sustained over a specified horizon with a given level of confidence. ${ }^{9}$ For instance, a one-day VaR of $\$ 1$ million at the $95 \%$ confidence level means that there is a $5 \%$ chance that the bank will lose more than $\$ 1$ million today. It seems almost natural to use a VaR-based model for economic capital; it tells the bank how much should be set aside to cover the "worst-case-scenario" losses. However, it has been argued that VaR lacks many of the features that are desirable in a valid risk measure (see, for example, Szegö (2002)). Furthermore, empirically, VaR does not perform well in forecasting future losses as documented by Berkowitz and O'Brien (2002). As a result, one would expect that VaR is unable to yield reliable estimates of economic capital and, in fact, it has been shown that VaR gives rise to biased estimates of economic capital (see Kupiec (1999) and Kupiec (2004)).

Some of the extreme limitations of VaR were perhaps illustrated in the recent Financial Crisis. ${ }^{10}$ There are two aspects in particular that the model used in this paper addresses directly: one is that VaR, and other existing methods of estimating bank capital, are not calibrated to market conditions; the second is that VaR focuses

\footnotetext{
${ }^{8} \mathrm{An}$ example is the RAROC methodology which is still widely used in these capacities within banks. See James (1996), Zaik, Walter, Retting, and James (1996), Stoughton and Zechner (2007) for more about RAROC and capital allocation in banks. An alternative framework for bank capital allocation and risk management is proposed by Froot and Stein (1998).

${ }^{9}$ For more about VaR, please see the book by Jorion (2006).

${ }^{10}$ For insight into the role of risk management in the recent financial crisis, please see Stulz (2008) and Jorion (2009).
} 
on the asset side of the bank's balance sheet without taking leverage or the sources of funding into account. This essentially ignores the bank's own risk of default which is a function of both sides of the balance sheet. Several researchers have begun to recognize the importance of bank liabilities and funding choices in determining bank capital. In fact, the Squam Lake Working Group (2009) explicitly calls for banks that finance their operations with a greater proportion of short-term debt should be required to set aside more capital. Kashyap, Rajan, and Stein (2008) suggest that the financial crisis was the proverbial "perfect storm" that arose from banks' excessive risk-taking in low quality assets (something that previous capital requirement standards should have addressed) combined with the overreliance on short-term debt to finance these risky investments. The latter can be problematic from two perspectives. First, there is the idea of "rollover risk" where the financial institution is unable to refinance maturing debt obligations due to poor liquidity in the short-term funding markets. However, even more fundamental is the idea that maturing debt provides a looming hurdle that banks must get over in order to survive. If the asset values are too low and maturing debts cannot be paid, the bank will be in a state of insolvency and possibly default. Both of these dimensions, funding liquidity and short-term default, should be incorporated into new models of bank capital. ${ }^{11}$

Additionally, the existing metrics rely on static measures using historical data and stale information. New research indicates that the use of market information monitoring and managing bank capital is critical, especially in times of crisis. Rapidly changing market conditions are not captured in static capital ratios. Hart and Zingales (2009) propose a mechanism for recapitalizing large financial institutions using credit default swaps (CDS). Under the Hart and Zingales (2009) proposal, if CDS spreads for a particular financial institution were to become too high then regulators would force the financial institution in question to take action regarding recapitalization. CDS spreads do convey information about the market's perception of a firm's likelihood of default; however, there are a few problems that could potentially arise from relying on the CDS market in the context of bank capital (and perhaps help

\footnotetext{
${ }^{11}$ The present paper focuses on the latter - i.e. default risk - in determining the amount of capital. Extending the model to include a liquidity factor is a nontrivial feat.
} 
support the case for using equity market information). First, as it currently stands, the CDS market only covers the largest and most liquid credit names. ${ }^{12}$ As a result, a CDS-based mechanism would not work for smaller, but publicly-traded, regional banks whereas one based on the equity market would. Second, some market participants believe that CDS contracts destabilized the markets during the recent financial crisis; in these instances it becomes difficult (if not impossible) to isolate the component of CDS spread movements due to true default risk versus those based on a vicious cycle of panic and speculation (see Stulz (2010)). Third, there is not a direct structural link between CDS spreads and the economics behind a bank's operations (i.e. degree of leverage, riskiness of the assets, and the interaction between the two). Above all of this, even if CDS spreads are reliable indicators of bank distress and triggers for when to recapitalize, this last point is critical: CDS spreads cannot be used to determine how much capital is needed to reduce default probabilities because of the lack of a structural link. ${ }^{13}$ It will be shown that only a structural credit risk model (with endogenous default) can be used in this capacity.

In fact, structural credit risk models can provide a good deal of insight into the problem of determining the appropriate amount of capital that is needed by a financial institution. Structural credit risk models take a contingent claims approach to valuing corporate securities and modeling the properties of financial distress (a brief taxonomy of structural credit risk models as they relate to banking firms is provided in the next section). Option-theoretic models have been used in the banking literature for risk-based deposit insurance. ${ }^{14}$ Despite relatively good success in using structural credit risk models for computing default probabilities and predicting corporate default, empirical studies typically exclude financial institutions. ${ }^{15}$ Leland (2009) discusses some of the difficulties in applying structural credit risk model to

\footnotetext{
${ }^{12}$ Chen, Cheng, Fabozzi, and Liu (2008) use the 60 most liquid CDS contracts in their empirical study, and note that "The liquidity drops substantially [after] the top 50 names." (p. 131)

${ }^{13}$ Along these lines CDS spreads can be viewed as "reduced-form".

${ }^{14}$ See Merton (1977), Marcus and Shaked (1984), Ronn and Verma (1986), Pennacchi (1987a), Pennacchi (1987b), Allen and Saunders (1993), and Cooperstein, Pennacchi, and Redburn (1995).

${ }^{15}$ E.g. Delianedis and Geske (2003), Leland (2004), Bharath and Shumway (2008).
} 
financial institutions. Two of the biggest issues are the high degree of leverage and the disproportionate use of short-term debt, including repurchase agreements.

The Vasicek (2002) model is a well-known approach for assessing the credit risk in a bank's loan portfolio and can be used within the capacity of VaR. However, although it is a credit risk model, the focus is still on the asset side of the balance sheet and therefore sheds little light on an integrated approach to modeling the capital needs of the bank. The integrated approach used in this paper is similar to the approach used in Ronn and Verma (1989) with at least two significant differences. First, Ronn and Verma (1989) use a single period, static model with one class of debt (i.e. the Black-Scholes-Merton model), whereas this paper proposes a multi-period, dynamic model with both junior and senior debt. Second, Ronn and Verma (1989) use deposit insurance to find the risk-based capital requirement, whereas the model proposed in this paper uses default probabilities to estimate the economic capital needed by the financial institution. The main distinctions from Ronn and Verma (1989) are nontrivial: the model developed in this paper is more robust in accounting for the bank's liability structure and does not rely on deposit insurance or any regulatory assumptions to compute the capital needs of the bank.

A structural credit risk model that is widely used in practice is the KMV model (see Crosbie and Bohn (2003)). However, as with many other structural credit risk models, the KMV model has little or no applicability to financial institutions. This is partly attributable to exogenous default condition where the entire liability structure is simplified to a linear combination of short-term debt and long-term debt, not taking into account seniority or the relevance of the individual components. It will be shown that endogenous default is a necessary condition for estimating capital needs with a structural credit risk model. Also, explicitly modeling the relationship between short-term debt, long-term debt, and the default process is especially critical for a financial institution. 


\section{A Structural Model of Bank Default}

\subsection{Structural Credit Risk Models and the Banking Firm}

Structural credit risk models began with the seminal works of Black and Scholes (1973) and Merton (1974), who noted that when a firm has debt in its capital structure the equity can be viewed as a call option on the firm's assets. Thus, the standard methods for pricing financial options can be applied to valuing corporate securities. The basic Black-Scholes-Merton (BSM) model provided an efficient, analytical method for calculating risky debt prices, credit spreads, and comparative statics, thereby taking the economics of credit risk to another level. Since then many extensions have been developed, in response to some of the restrictive and unrealistic assumptions behind the basic BSM model. ${ }^{16}$ One class of extensions are the "barrier" structural models where default can occur at any time and is the result of the asset value process hitting a barrier. Many of these models assume an exogenous default barrier (Black and Cox (1976), Longstaff and Schwartz (1995), Collin-Dufresne and Goldstein (2001)) although the Leland (1994) and Leland and Toft (1996) models include an endogenous default barrier that is solved for within the model. Another structural credit risk model with endogenous default is the compound option model of Geske (1977). These endogenous default models are critical to understanding the structural credit risk model developed in this paper; hence, they will be discussed in more detail.

Structural credit risk models are commonly used to compute default probabilities. Within the original BSM framework, the probability that the call option is not exercised at time $T$ is the probability that the firm defaults; that is because if the market value of the firm's assets is not greater than the face value of the debt, then shareholders will let their option expire and leave the assets to the debt holders. The extensions that include a continuous default barrier compute default probabilities by

\footnotetext{
${ }^{16}$ Perhaps the most notorious of these assumptions is that the firm has only one class of debt outstanding in the form of pure discount bonds maturing at a fixed time $T$. Accordingly, many of these extensions allow for multiple classes of debt, default prior to maturity, and coupon payments, although some models also include stochastic interest rates and jumps in the asset value process.
} 
the first passage density. The [discrete-time] compound option structural model actually computes default probabilities at every cash flow time (i.e. whenever a payment, principal or interest, is due to bondholders). This gives rise to a term structure of default probabilities.

An appropriate structural credit risk model for a banking firm must be flexible enough to account for how funding decisions are made in different market conditions but also capture the complex liability structure that is an inherent characteristic of financial institutions. Another important feature is endogenous default, especially for dealing with bank capital, as is argued below.

The Leland and Toft (1996) model has endogenous default and is attractive for several reasons. First of all, there is a closed-form solution for the values of debt and equity, as well as default probabilities and the default barrier. Furthermore, it is assumed that all debt is rolled-over which, in normal market conditions, is in line with the practices of financial institutions. However, the Leland and Toft (1996) model does not capture all of the features of a bank because it assumes that there is only one class of debt with a fixed maturity and the debt structure is fixed.

The compound option structural credit risk model of Geske (1977) also has endogenous default. The model allows default to occur whenever a cash flow is due, rather than the two extremes of defaulting at maturity (as with European options and the original BSM model) or defaulting anytime between now and maturity (as with barrier models). This can then be used to model coupon-paying debt, where default can occur if it is not economically feasible to make an interest and/or principal payment; or it can be used to model a complex seniority or maturity structure where debt holders are to be paid sequentially. This is a practical way to capture the realistic feature of cross-default provisions in debt contracts.

When there are just two cash flows, the model can be solved analytically as shown by Geske (1979). It is also shown that there is an explicit leverage effect that causes the volatility to change with the value of the underlying assets. Geske and Johnson (1984) appropriately specify the default conditions when there are two distinct classes 
of debt, which leads to the correct closed-form expression for the intertemporal values of equity and junior debt.

This compound option structural model provides a consistent and intuitive framework for valuing corporate securities and quantifying credit risk. Furthermore, the model captures the complex and important capital structure of a bank rather nicely. The model is simple enough where it can be computed analytically, but still has the information regarding the seniority structure of debts and the inherent compoundoptionality in the decision to default.

The drawback of the compound option structural model is that it is assumed that all debt obligations are satisfied by issuing new equity. This implies that the firm being analyzed will have a leverage ratio that decreases systematically over time and it will ultimately become an all-equity firm. There are very few firms that practice such extreme de-leveraging, especially in the banking industry. ${ }^{17}$ A structural model that preserves endogenous default but that has some mechanism for rolling-over debts (especially those that are short-term in nature), as in Leland and Toft (1996), might be more appropriate for financial institutions.

The model used in this paper draws from the most promising aspects of existing structural models with the intention of developing a practical and realistic credit-riskbased approach to estimating bank capital. It is based on the Geske compound option structural credit risk model, but includes a dynamic implementation. When used in this dynamic capacity, the compound option structural model has the interpretation that, as long as default probabilities are sufficiently low approaching the first cash flow (i.e. payment to short-term, senior creditors), some or all of the debts will be rolled over before the specified maturity time in accordance with the bank's funding policy. As a result, this dynamic implementation introduces the spirit of a model such as Leland and Toft (1996). In the model, default is endogenous and is triggered when the value of the bank's assets is too low to justify the sale of any new equity. The inability to raise fresh capital can be thought of as the driving force of bank distress, especially

\footnotetext{
${ }^{17}$ Adrian and Shin (2010) show that financial institutions tend to actively manage their leverage ratios in a procyclical manner.
} 
during the recent financial crisis. Therefore, the endogenous default condition given by the model is crucial to understand the events that unfolded during the crisis. Furthermore, endogenous default is also necessary to solve for economic capital.

\subsection{Assumptions and Model Setup}

First, it should be noted that the structural credit risk model developed in this paper assumes that financial institutions exist in a world with no market frictions. Specifically, it is assumed that there are no taxes, no distress costs, no transaction costs, and perfect liquidity. The assumption of perfect liquidity implies that there is no rollover risk - a crucial point for the dynamic implementation of the model. Since there are no market frictions, it follows that the bank's capital structure is exogenous; that is, no claim is made with respect to the optimal level of bank capital. Rather, the goal is to find the appropriate level of economic capital needed to keep default probabilities within a reasonable range given the bank's current capital structure. Despite the exclusion of such frictions, the insights that are given by this model are useful nonetheless. The model highlights the fact that static measures of capital adequacy, such as a fixed percentage of assets, are arbitrary and do not capture the true health of a financial institution. Rather, a dynamic approach that is forward-looking and tied to market conditions is more appropriate for determining the capital needs. One implication is that capital requirements may be time-varying and conditional upon the health of the particular bank and the financial system as a whole. The model provides a quantitative and objective method for determining how much economic capital a financial institution needs in good times and bad. All of this can be demonstrated without the presence of market frictions. The nontrivial task of extending the model to account for one or more of the above market frictions is left for future research.

In addition to the fact that the bank's capital structure is exogenous, no claim is made regarding the optimality of contracts in the model. It is taken as given that debt exists, and that banks rely on it as a primary source of funding. This assumption may be justified by casual empiricism, which indicates that banks primarily rely on 
debt to fund their operations, or theoretically where banks, as liquidity providers, convert short-term, liquid liabilities to long-term, illiquid assets.

To set up the model mathematically, several additional assumptions have to be made. First, assume that the market value of the bank's portfolio of assets (i.e. loans, investment securities, etc.) evolves according to a Geometric Brownian Motion. That is, at time $t$ the asset value process is given by the stochastic differential equation

$$
d V_{t}=r_{t} V_{t} d t+\sigma_{V} V_{t} d W
$$

where $d W_{t}$ represents a standard Brownian increment under the risk-neutral probability measure. ${ }^{18}$ In Equation (1) $r_{t}$ represents the risk-free interest rate at time $t$ and $\sigma_{V}$ is the asset volatility. Neither the interest rates nor asset volatility are stochastic, another assumption of the model.

Now, assume that there are two general classes of debt: senior debt with face value $F_{1}$ maturing at time $T_{1}$ and junior debt with face value $F_{2}$ maturing at time $T_{2}$, where $T_{1}<T_{2}$. Here, the short-term, senior debt can be time deposits, repurchase agreements, federal funds purchased, and/or other similar claims. While many of these claims are secured, they need not be; the key feature is that they are expected to be re-paid by time $T_{1}$ or have priority in the event of a liquidation. The long-term, junior debt can be thought of as subordinated debentures, which are issued by many financial institutions and featured prominently in the market discipline literature. The subordinated debentures lie just above equity in terms of seniority, but since they are unsecured, have longer maturities, and have lower priority, they bear more risk than the senior debt. Figure 1 illustrates this capital structure with a simplified balance sheet for a typical bank. This two-tiered liability structure implies that the bank's equity is a compound call option on the bank's assets. First, short-term, senior creditors must be paid; then, the junior, long-term debt is paid; and, finally, whatever

\footnotetext{
${ }^{18}$ The risk-neutral measure is used for at least two reasons: first, it does not require the estimation of the risk premium for individual banks. Since at any given time the current risk premium is unobservable, attempting to estimate the risk premium introduces yet another degree of uncertainty and potential for model error. Rather, it is more straightforward to use the risk-free rate which is observable. Second, it can easily be shown that under certain conditions the risk-neutral measure serves as an upper bound on true default probabilities.
} 
is left goes to the shareholders (the residual claimants). Note that the usual balance sheet equality must hold [in market value]: $V_{t}=S_{t}+J_{t}+E_{t}$, where $S_{t}$ is the market value of the short-term, senior debt at time $t, J_{t}$ is the market value of the long-term, junior debt at time $t$, and $E_{t}$ is the market value of the equity at time $t$. Next, valuation of the bank's corporate securities will be discussed. The value of all three security classes- equity, junior debt, and senior debt- can be solved for in closed-form within the framework that has been established to this point.

\subsection{Valuation}

To value the securities within the compound option framework it is helpful to visualize the default process as a binomial tree. In Figure 2 the solid nodes represent survival states, whereas the dashed nodes represent default states. The accompanying table shows the value of the corporate securities (equity, junior debt, and senior debt) at each node. Solving the expectations at node A gives rise to the closed-form valuation equations below.

Moving from node $\mathrm{A}$ to node $\mathrm{B}$ means that the bank survives to time $T_{1}$ and the senior debt holders will be paid. Survival at the first cash flow time, $T_{1}$, depends on the asset value relative to the default barrier, $\bar{V}$, which is endogenously determined. Precisely how the endogenous default barrier is determined will be discussed in detail below (see Section 3.4). Since, at node B, the asset value is greater than the default barrier, the first cash flow obligation, $F_{1}$ is satisfied in full and all that remains are the junior debt and equity claims. At this point, the model is identical to the standard Black-Scholes-Merton (BSM) structural model. It is no surprise that the value of equity at time $T_{1}, E_{T_{1}}$, is given by their famous equation for pricing a European call option, with strike price and time-to-expiration $T_{2}-T_{1}$. This will be an important point when deriving the endogenous default boundary. Accordingly, the value of the subordinated debt at time $T_{1}, J_{T_{1}}$, is equal to the value of a covered call or a put option attached to a risk-free loan of maturity $T_{2}-T_{1}$ as per put-call parity. The

probability of getting to node $\mathrm{B}$, or equivalently the probability that $V_{T_{1}}>\bar{V}$, is the 
short-term survival probability, denoted as $p_{1}$ in Figure 2. All of the probabilities are known in closed-form and derived in Section 3.4.

On the other hand, if the value of the bank's assets are less than or equal to the default barrier, then the bank will hit the default state at node $\mathrm{C}$. There is a very important subtlety that must be pointed out here. Node $\mathrm{C}$ is actually further broken down into two states, $C_{1}$ and $C_{2}$, which represent partial versus total default, respectively. $C_{1}$ is referred to as "partial" default, because senior debt holders are paid in full but asset value is not high enough to pay junior debt holders so the latter party receive only the residual payment. In and near this distressed state, equity has no value and the bank's subordinated debentures will behave more like equity rather than debt. $C_{2}$, on the other hand, represents total default where neither equity holders nor junior debt holders are paid, and the senior debt holders will receive whatever value the assets are worth at default time .

In the static compound option framework if the firm makes it to node $\mathrm{B}$, then new equity is issued at the current market price and used to finance the payment to the senior creditors. Thus, once the short-term, senior debt holders are paid at node $\mathrm{B}$ the leverage of the firm is reduced by $F_{1}$ and only long-term, junior debt remains outstanding. As mentioned above, the model then reduces to the standard BSM setup. If the value of the assets at time $T_{2}$ is greater than the face value of the junior debt $\left(V_{T_{2}}>F_{2}\right)$ then the bank will end up in the terminal survival state, represented by node D in the lattice. The assets are liquidated, junior creditors are repaid what they are owed, and shareholders receive the residual value $V_{T_{2}}-F_{2}$. However, if the value of the assets is less than or equal to the face value of the junior debt $\left(V_{T_{2}} \leq F_{2}\right)$ then the bank will end up in the terminal default state, represented by node E, with conditional probability of $1-p_{2}$. This is the "conditional" default probability because it is conditional upon the bank's survival to time $T_{1}$.

From the perspective at node A the model seems to be a reasonable, albeit simple, representation of the scenario faced by a typical financial institution. However, once node $\mathrm{B}$ is transcended, this leads to a rather unrealistic circumstance in the static world. Recall, that the traditional static compound option structural model has the 
unfavorable feature that, since debt is paid down by issuing new equity, leverage is systematically reduced over time ultimately leading to an all-equity firm. Fortunately, with the dynamic implementation proposed in this paper, the bank will never get to that point. Every time the model is run, the lattice effectively starts over and the analysis is from the perspective of node $\mathrm{A}$ all over again. Essentially, at time $T_{1}$ when payment to the senior creditors is due, the bank will either default or roll-over some or all of their short-term debt. This dynamic implementation is described below in Section 3.5.

The value of the securities can be determined at node $\mathrm{A}$ (time $t=0$ ) by taking the discounted expected value of the future cash flows at each of the subsequent nodes. For equity and junior debt this results in nested expectations. Consequently, the assumption that Geometric Brownian Motion is the underlying stochastic process ensures that the solution is a function of the bivariate normal distribution, which is very manageable.

Now, for any time $t, 0 \leq t<T_{1}$, evaluating the expectations at $t$ gives the closedform expressions for valuing all of the bank's claims. Equity is a compound call on the bank's assets in that shareholders have a claim to

$$
\mathbb{E}\left[e^{-r \tau_{1}} \max \left\{E_{T_{1}}-F_{1}, 0\right\} \mid V_{t}\right]
$$

where $E_{T_{1}}$ is equal to the value of a European call option at time $T_{1}$, which is not known at time $t$. Let $\tau_{1}=\left(T_{1}-t\right)$ be the time between $t$ and the short-term, senior debt maturity $T_{1}$ and $\tau_{2}=\left(T_{2}-t\right)$ be the time between $t$ and the long-term, junior debt maturity $T_{2}$. The expectation given in Equation (2) is equal to: ${ }^{19}$

$$
E_{t}=V_{t} N_{2}\left(h_{1}^{+}, h_{2}^{+} ; \rho\right)-F_{2} e^{-r \tau_{2}} N_{2}\left(h_{1}^{-}, h_{2}^{-} ; \rho\right)-F_{1} e^{-r \tau_{1}} N\left(h_{1}^{-}\right)
$$

where $h_{1}^{+}=\frac{\ln \left(\frac{V_{t}}{V}\right)+\left(r+\frac{\sigma^{2}}{2}\right) \tau_{1}}{\sigma \sqrt{\tau_{1}}}$

$$
h_{1}^{-}=\frac{\ln \left(\frac{V_{t}}{V}\right)+\left(r-\frac{\sigma^{2}}{2}\right) \tau_{1}}{\sigma \sqrt{\tau_{1}}}=h_{1}^{+}-\sigma \sqrt{\tau_{1}},
$$

\footnotetext{
${ }^{19}$ For a derivation please see Geske (1977), Geske (1979), and Geske and Johnson (1984).
} 
$h_{2}^{+}=\frac{\ln \left(\frac{V_{t}}{F_{2}}\right)+\left(r+\frac{\sigma^{2}}{2}\right) \tau_{2}}{\sigma \sqrt{\tau_{2}}}$,

$h_{2}^{-}=\frac{\ln \left(\frac{V_{t}}{F_{2}}\right)+\left(r-\frac{\sigma^{2}}{2}\right) \tau_{2}}{\sigma \sqrt{\tau_{2}}}=h_{2}^{+}-\sigma \sqrt{\tau_{2}}$,

$N($.$) denotes the cumulative standard normal distribution,$

$N_{2}$ (.) denotes the cumulative bivariate standard normal distribution,

and correlation $\rho=\sqrt{\tau_{1} / \tau_{2}}$ which follows from the properties of Brownian Motion.

$\bar{V}$ is the endogenous default boundary, derived in Section 3.4.

The senior debt is to be paid at time $T_{1}$. If the market value of the assets at that time is greater than $\bar{V}$, then senior debt holders will be paid the amount $F_{1}$ in full. However, if the market value of the assets is less than or equal to $\bar{V}$ and less than the face value of the senior debt, then there is [total] default at time $T_{1}$. In this case, the assets will be liquidated and senior debt holders will only recover a portion of what they are owed; specifically they will recover the market value of the assets at the time of default, $T_{1}$. Thus, the value of the short-term, senior debt at time $t$ is given by the expectation

$$
\mathbb{E}\left[e^{-r \tau_{1}} \min \left\{V_{T_{1}}, F_{1}\right\} \mid V_{t}\right]
$$

It is relatively straightforward to show that the expectation given in Equation (4) is equal to

$$
S_{t}=V_{t}\left[1-N\left(k^{+}\right)\right]+F_{1} e^{-r \tau_{1}} N\left(k^{-}\right),
$$

where $k^{+}=\frac{\ln \left(\frac{V_{t}}{F_{1}}\right)+\left(r+\frac{\sigma^{2}}{2}\right) \tau_{1}}{\sigma \sqrt{\tau_{1}}}$ and $k^{-}=\frac{\ln \left(\frac{V_{t}}{F_{1}}\right)+\left(r-\frac{\sigma^{2}}{2}\right) \tau_{1}}{\sigma \sqrt{\tau_{1}}}=k^{+}-\sigma \sqrt{\tau_{1}}$.

Then, finally, there is the bank's junior debt which has the interesting property that when asset values are well above the default boundary they are a fixed claim and their prices behave like debt, but in times of distress they are a residual claim and their prices behave like equity. The model captures this characteristic of bank subordinated debentures well. The value of the long-term, junior debt at time $t$ is given by the expectation:

$$
\mathbb{E}\left[e^{-r \tau_{1}}\left(\left(J_{T_{1}} \cdot \mathbb{I}_{\left\{V_{T_{1}}>\bar{V}\right\}}\right)+\left(\max \left\{V_{T_{1}}-F_{1}, 0\right\} \cdot \mathbb{I}_{\left\{V_{T_{1}} \leq \bar{V}\right\}}\right)\right) \mid V_{t}\right]
$$


where $\mathbb{I}_{\{V>\bar{V}\}}$ is the indicator function that equals 1 if $V>\bar{V}$ and 0 otherwise.

To obtain the closed-form solution for the long-term, junior debt the expectation given in Equation (6) can be evaluated directly or, since the expectation for shortterm, senior debt is considerably more straightforward, the fact that $V_{t}=E_{t}+J_{t}+S_{t}$ can be used to solve for $J_{t}=V_{t}-E_{t}-S_{t}$. Subtracting Equation (3) and Equation (5) from $V_{t}$ gives:

$J_{t}=V_{t}\left[N\left(k^{+}\right)-N_{2}\left(h_{1}^{+}, h_{2}^{+} ; \rho\right)\right]+F_{1} e^{-r \tau_{1}}\left[N\left(h_{1}^{-}\right) N\left(k^{-}\right)\right]+F_{2} e^{-r \tau_{2}} N_{2}\left(h_{1}^{-}, h_{2}^{-} ; \rho\right)$

where all of the terms are as previously defined in Equation (3) and Equation (5).

Although asset volatility is assumed to be constant, equity volatility is not constant but rather changes as a function of asset value and other parameters in the model. This was first shown by Geske (1979). Equity, being a compound option on the underlying asset, has its own stochastic dynamics which can be specified using Ito's Lemma. From the Ito expansion the volatility term for equity is

$$
\sigma_{E}=\frac{\partial E}{\partial V} \frac{V}{E} \sigma_{V}
$$

The partial derivative $\frac{\partial E}{\partial V}$ can be found by differentiating Equation (3) with respect to asset value and is known as the "equity delta":

$$
\frac{\partial E}{\partial V}=N_{2}\left(h_{1}^{+}, h_{2}^{+} ; \rho\right)
$$

Plugging Equation (9) into Equation (8) gives

$$
\sigma_{E}=N_{2}\left(h_{1}^{+}, h_{2}^{+} ; \rho\right) \frac{V}{E} \sigma_{V}
$$

This equation says that, holding everything else constant, as more leverage is introduced the equity volatility becomes greater than the asset volatility. This leverage effect is consistent with standard corporate finance theory which says that leverage 
increases the riskiness of a firm's equity as financial risk is compounded on top of the inherent total business risk (as proxied by $\sigma_{V}$ ).

\subsection{Endogenous Default and Default Probabilities}

In both the original [static] compound option structural model as well as the dynamic implementation presented in this paper the default condition arises from the fact that the firm must have access to capital in order to survive. At time $T_{1}$, when the shortterm, senior debt is due, the firm must be able to raise enough capital to satisfy the pending obligations. Given the assumption that capital is raised in a frictionless market, equity can always be issued at the current market prices. As the market value of equity approaches zero, the firm will find itself under increasing pressure to raise the funds needed to service the outstanding debt. Recall that equity, in turn, is a function of the value of the firm's assets. Thus, there must be some "breakeven" asset value such that the market value of equity is high enough that a new issuance will just satisfy the next cash flow, leaving nothing for the residual claimants. In other words, the default condition maintains that equity must have positive value for survival. ${ }^{20}$ Mathematically, the default boundary is the asset value, $V_{T_{1}}=\bar{V}$, that is the internal solution to the integral equation

$$
E(\bar{V})-F_{1}=0
$$

It follows from Equation (11) that

$$
\bar{V}=F_{1}+J_{T_{1}}
$$

where $J_{T_{1}}$ is the market value of the long-term, junior debt at the time the senior debt holders are paid (this was defined in Section 3.3). In order to find the default

\footnotetext{
${ }^{20}$ This is the same as the default condition in the Leland-Toft model; see Leland and Toft (1996), p. 994.
} 
boundary, Equation (11) can be solved so that

$$
F_{1}=E(\bar{V})=\bar{V} N\left(d_{+}^{*}\right)-F_{2} e^{-r\left(T_{2}-T_{1}\right)} N\left(d_{-}^{*}\right)
$$

where $d_{+}^{*}=\frac{\ln \left(\frac{\bar{V}}{F_{2}}\right)+\left(r+\frac{\sigma^{2}}{2}\right)\left(T_{2}-T_{1}\right)}{\sigma \sqrt{T_{2}-T_{1}}}$ and $d_{-}^{*}=\frac{\ln \left(\frac{\bar{V}}{F_{2}}\right)+\left(r-\frac{\sigma^{2}}{2}\right)\left(T_{2}-T_{1}\right)}{\sigma \sqrt{T_{2}-T_{1}}}$.

Solving for $\bar{V}$ in Equation (13) gives the endogenous default boundary. If the asset value at time $T_{1}$ is less than this amount, then the firm will not be able to raise capital and will default. Once the default boundary has been found, the default probabilities can be specified in closed-form. ${ }^{21}$

The short-term survival probability, or the probability that the bank survives up to time $T_{1}$, is:

$$
Q\left(T_{1}\right)=\operatorname{Pr}\left\{V_{T_{1}}>\bar{V}\right\}=N\left(h_{1}^{-}\right)
$$

where $Q(\cdot)$ denotes the survival probability under the risk-neutral measure and $N\left(h_{1}^{-}\right)$is the cumulative standard normal distribution function as defined in the valuation equations above (see, e.g., Equation (3)).

At time $T_{1}$, either the bank pays the senior creditors (and survives) or it defaults. Therefore, the short-term default probability is:

$$
D P\left(T_{1}\right)=\operatorname{Pr}\left\{V_{T_{1}} \leq \bar{V}\right\}=1-\operatorname{Pr}\left\{V_{T_{1}}>\bar{V}\right\}=1-N\left(h_{1}^{-}\right)=N\left(-h_{1}^{-}\right)
$$

which follows directly from Equation (14) and the laws of probability for mutually exclusive events.

The total survival probability, or the joint probability of the bank surviving to both $T_{1}$ and $T_{2}$, is:

$$
Q\left(T_{2}\right)=\operatorname{Pr}\left\{\left(V_{T_{1}}>\bar{V}\right) \&\left(V_{T_{2}}>F_{2}\right)\right\}=N_{2}\left(h_{1}^{-}, h_{2}^{-} ; \rho\right)
$$

\footnotetext{
${ }^{21}$ The derivations are given in a Technical Appendix available from the author upon request.
} 
where, again, $Q(\cdot)$ denotes the survival probability under the risk-neutral measure and $N_{2}\left(h_{1}^{-}, h_{2}^{-} ; \rho\right)$ is the cumulative bivariate standard normal distribution for two jointly distributed standard normal random variables with correlation $\rho$ as defined in the valuation equations above (see, e.g., Equation (3)).

Since the bank cannot default at time $T_{2}$ without first having survived to time $T_{1}$ only the conditional forward default probability exists. That is, the probability that the bank defaults at (or survives to) time $T_{2}$ given that the bank defaulted in $T_{1}$ is undefined. In other words, short-term default is an absorbing state; the bank cannot emerge from bankruptcy. Thus, the forward default probability can be computed once the short-term survival probability and the total survival probability are known simply by applying Bayes' Theorem. The forward default probability is defined as the probability that the long-term debt obligations will not be satisfied given that the short-term debt obligations have been satisfied, or $\operatorname{Pr}\left\{V_{T_{2}} \leq F_{2} \mid V_{T_{1}}>\bar{V}\right\}$. This is equal to one minus the conditional survival probability, or $1-\operatorname{Pr}\left\{V_{T_{2}}>F_{2} \mid V_{T_{1}}>\bar{V}\right\}$. Since Bayes' Theorem says that a conditional probability is equal to the joint probability of both events occurring divided by the unconditional probability of the event upon which it is being conditioned, then the conditional survival probability is the total survival probability divided by the short-term survival probability. The forward default probability, or the probability of the bank defaulting at $T_{2}$ given that it survived to $T_{1}$, is then one minus the conditional survival probability:

$$
\begin{gathered}
D P\left(T_{2}\right)=\operatorname{Pr}\left\{V_{T_{2}} \leq F_{2} \mid V_{T_{1}}>\bar{V}\right\} \\
=1-\operatorname{Pr}\left\{V_{T_{2}}>F_{2} \mid V_{T_{1}}>\bar{V}\right\}=1-\frac{\operatorname{Pr}\left\{\left(V_{T_{2}}>F_{2}\right) \&\left(V_{T_{1}}>\bar{V}\right)\right\}}{\operatorname{Pr}\left\{V_{T_{1}}>\bar{V}\right\}} \\
=1-\frac{N_{2}\left(h_{1}^{-}, h_{2}^{-} ; \rho\right)}{N\left(h_{1}^{-}\right)}
\end{gathered}
$$

where, it has already been established that the short-term and total survival probabilities, are $N\left(h_{1}^{-}\right)$and $N_{2}\left(h_{1}^{-}, h_{2}^{-} ; \rho\right)$, respectively. Bayes' Theorem gives the conditional survival probability as $\frac{N_{2}\left(h_{1}^{-}, h_{2}^{-} ; \rho\right)}{N\left(h_{1}^{-}\right)}$and the conditional default probability then follows from mutual exclusivity (the bank cannot both survive and fail at $T_{2}$ ). 
Proposition: The short-term default probability, given by Equation (15), is the key metric to assess banks' solvency in the context of economic capital.

While critics may contend that this is a myopic approach, it is quite the contrary. Since it is a function of the default boundary, $\bar{V}, D P\left(T_{1}\right)$ contains all relevant information including asset risk, endogenous default, and the complete liability structure - not only the short-term debt but also the expectation of the bank's ability to pay its long-term debt in the future.

The forward default probability, on the other hand, does not capture all of this information and is much less relevant for the analysis of financial institutions. To see why, recall the key assumption for the compound option structural model: when debt is due, new equity is issued and the proceeds are used to finance the debt payment. In the case where there are just two classes of debt the degree of leverage in the firm's capital structure will fall immediately after the first payment is made. This is because that first class of debt will be replaced entirely with equity. ${ }^{22}$ This is especially problematic for financial institutions for two reasons. First of all, financial institutions tend to have a lot of short-term, senior debt, so assuming that it will all be paid off by issuing new equity results in a massive, very unnatural drop in leverage for a firm that is typically characterized by high leverage. Second, as mentioned earlier, financial institutions tend to rollover short-term debts. This means that the true forward default probability should not only use the junior, long-term debt in creating the forward default boundary but also some portion of the short-term debts that had been rolled over.

As a result, the forward default probabilities calculated with Equation (17) are biased downward. The implicit deleveraging that is built into the compound model creates the unrealistic impression that bank default risk declines over time. Of course, this is not what is really going on but the static compound option model distorts future expectations along these lines. If, however, the model is periodically recalibrated then

\footnotetext{
${ }^{22}$ At this point, the model would collapse to the standard BSM structural model as described earlier in the Section.
} 
a more accurate picture of the default risk can be created. The short-term default probability, or $D P\left(T_{1}\right)$ as given by Equation (15), still represents a valid measure of the financial institution's default risk since it takes the entire liability structure into account, but is also updated to reflect any short-term debt that may have been rolledover. And because it relies on the endogenous default boundary this is an internally consistent metric for determining the capital needs for a financial institution. In the next subsection the proposed dynamic implementation is described. Each time the model is recalibrated new inputs are used including the most recent liability structure. In this dynamic framework a financial institution's default risk, and subsequently the economic capital, can be analyzed in a way that is consistent with the actual financing strategy (i.e. some of the debts are rolled-over).

\subsection{Dynamic Implementation}

There are several aspects of the original [static] compound option model that make it unattractive, especially for analyzing financial institutions. The first is the issue that was just brought up; namely that immediately after the short-term, senior debt is paid the model has the financial institution's leverage drop dramatically. This leads to the next problem which is more practical in nature. As noted above, in practice financial institutions tend to rollover debts, especially short-term liquid liabilities. While explicitly modeling this rollover decision (i.e. when, how much, and which debts to rollover, etc.) can be tricky, a good structural credit risk model for financial institutions should account for it somehow. Lastly, there is yet another problem with the static compound option model. Since equity is a compound call option, as $t$ approaches $T_{1}$ the equity value will drop purely from time decay (i.e. "theta"). That is, even if the bank fundamentals stay the same (the asset value, volatility, etc.) there will be a decline of the equity value over time. This implies that the bank's shareholders have an incentive to arrange for the short-term debt to be rolled-over sometime before $T_{1}$ when the short-term creditors would agree to it. ${ }^{23}$ In this paper

\footnotetext{
${ }^{23}$ Presumably this would be when $D P\left(T_{1}\right)$ is close enough to zero since a creditor is not going to willingly extend the maturity on what they are already owed if it looks like the borrower might default in the near future.
} 
a dynamic implementation of the compound option structural model is proposed to address these problems.

In contrast to the static compound option model, the dynamic implementation employed in this paper allows the user to run and recalibrate the model every day (or more often if there is a need) with updated data from the equity markets and about the liability structure of the bank. Every time the model is run, only the existing liabilities at that particular moment are taken into account. This implies that all previous liabilities were retired in some way that is consistent with the bank's actual funding strategy. As the liability structure changes, the model is recalibrated and adapts to the new liabilities. In this context, the default condition says that as long as the firm can issue new equity at the current market price then it will survive to time $T_{1}$. That does not mean that the bank will issue equity. Upon meeting this survival criterion, it will choose to rollover some proportion of the debts and finance the rest with equity capital. This decision is exogenous to the model and reflects the bank's actual funding strategy.

Recall from earlier that the dynamic implementation has the interpretation that, as long as default probabilities are sufficiently low as $t$ approaches $T_{1}$, some or all of the debts will be rolled over before maturity. If default probabilities are not "sufficiently low" within this framework it means that there is very little chance of being able to raise capital to satisfy the pending debt obligations. Thus, the conditions that fresh capital can be raised and that debt can be rolled over are both sufficient and necessary conditions for each other in the model. Furthermore, since there is no notion of liquidity risk in the model, the rollover occurs with probability one. ${ }^{24}$

The dynamic implementation is very straightforward: every period, the model is recalibrated and re-run with updated inputs (market information, liability structure, interest rates, etc.). This will give new outputs including the default probabilities. The long-term forward default probability will still be biased downward, but the short-term default probability is a valid measure of bank risk since it is a function

\footnotetext{
${ }^{24}$ Recent papers by He and Xiong (2011), Acharya, Gale, and Yorulmazer (2010), and Morris and Shin (2009) develop models that incorporate both credit risk and liquidity risk in an effort to quantify this "rollover risk".
} 
of the entire liability structure and the endogenous default boundary. Over time, as the financial institution retires some debts and rolls-over other debt, the liability structure will change. This new liability structure combined with changing market information will, in turn, result in new default probabilities which may indicate that more economic capital is needed to ensure the solvency of the financial institution in question. The precise quantification of economic capital as a model output is defined in the next subsection.

\subsection{Economic Capital}

The feature of endogenous default makes the model well-suited to solve for the economic capital deficiency of the financial institution. The economic capital deficiency (ECD) is the additional amount of capital needed to bring short-term default probabilities below a specified acceptable level. Later in this subsection the algorithm for computing the ECD with the model is described. First, however, "economic capital" within this context should be defined.

Economic capital, in the context of the structural credit risk model, can be defined as the difference between the market value of the bank's assets and the market value of the bank's liabilities. The problem is that neither of those quantities is directly observable. However, from the balance sheet identity it must equal the market value of the bank's equity which is observable. Since equity is a compound call option in the model, the implied market value of the bank's assets can be extracted from market information. The market information specifically being used are the market value of equity and equity volatility. Using an iterative procedure (described in Section 4.3), the market value of the bank's assets and the asset volatility can be computed as two equations in two unknowns. This gives rise to the metric for economic capital that shall be referred to as the Model-Implied Economic Capital Ratio (MIEC_Ratio):

$$
\text { MIEC_Ratio }=\frac{E_{t}}{V_{t}}
$$


where $E_{t}$ is the market value of the bank's equity at time $t$, given by Equation (3), and $V_{t}$ is the implied market value of the bank's assets. It is "implied" from the equity market information and the structural credit risk model. The MIEC_Ratio is very useful in the analysis of bank capital because it looks at the relative size of the equity buffer given the current market conditions. When the market assigns lower values to the bank's assets and/or there is a lot of uncertainty regarding the true value of the bank's assets, it is vital that the equity buffer be sufficient enough to absorb additional losses. Since the model is forward-looking, it helps avoid some of the inconclusive or erroneous inferences that can be made when relying on backward-looking historical metrics. Indeed, the empirical analysis of BHCs during the Financial Crisis includes a comparison of the MIEC_Ratio with the Risk-Based Regulatory Capital Ratio (RBRC_Ratio).

The model is also useful for determining the economic capital deficiency (ECD) for a distressed financial institution. The ECD represents the amount of additional capital needed to bring short-term default probability below the specified $\alpha$-level, where $\alpha$ is the highest acceptable short-term default probability. It has already been shown that the short-term default probability is a function of the asset value, asset volatility, liability structure (size and timing of the promised cash flows), and the risk free rate. This is denoted as $D P_{T_{1}}\left(V, \sigma_{V}, F_{1}, F_{2}, T_{1}, T_{2}, r_{f}\right)$. To isolate the effect that a cash infusion has on the default probability, assume that $V$ and $\sigma_{V}$ are the only parameters that change. Therefore, the rest of the arguments can be dropped so that the short-term default probability is denoted as $D P_{T_{1}}\left(V, \sigma_{V}\right)$. The solvency condition as specified by the bank risk manager is that $D P_{T_{1}}\left(V, \sigma_{V}\right) \leq \alpha$.

A few things should be said about the assumptions underlying the computation of ECD in the model. First of all, it is assumed that there are no explicit transaction costs associated with raising the additional capital. Furthermore, no claim is made about how the capital is raised; rather assume it comes entirely from some exogenous source (i.e. dropped from a helicopter, a la Friedman (1969)). This is because the focus of the model is to determine how much economic capital banks need, not the recapitalization mechanism for undercapitalized banks (that is left for future research). 
Finally, it is assumed that this fresh capital is held in cash on the banks balance sheet. This is not unreasonable and the importance of this assumption is given below. Let $C$ denote the amount of fresh capital raised; after the hypothetical capital infusion the bank has total assets valued at:

$$
V^{*}=V+C
$$

Since cash has no volatility and is completely uncorrelated with the risky assets in the bank's portfolio, the new asset volatility can be computed as a weighted average:

$$
\sigma_{V^{*}}=\left(\frac{V}{V^{*}}\right) \sigma_{V}+\left(\frac{C}{V^{*}}\right) 0=\left(\frac{V}{V^{*}}\right) \sigma_{V}
$$

The cash assumption allows the economic capital to simultaneously achieve two objectives: on the one hand, it increases the market value of the bank's assets by an amount $\Delta V=C$; at the same time it reduces the total risk of the bank's portfolio. Both of these, in isolation, will result in lower default probabilities. The combination of increased asset value along with decreased asset risk gives a proverbial "one-two punch" in combating bank distress.

The ECD is therefore the solution to the following nonlinear optimization problem:

$$
E C D=\inf \left\{C: D P_{T_{1}}\left(V^{*}, \sigma_{V^{*}}\right) \leq \alpha\right\}
$$

subject to the constraints in Equation (19) and Equation (20).

That is, find the smallest $C$ such that the short-term default probability is below the specified level, $\alpha$. This can be done numerically and, in fact, a simple search algorithm was used to perform the empirical analysis in Section 5.

The reason that an infimum is used in Equation (21) is because the conventional wisdom is that banks prefer to have as little equity capital as possible. The existence of minimum capital requirements is a testament to this idea. It has traditionally been argued that capital is the more expensive financing choice and that banks can keep their cost of capital lower by using more debt in the capital structure. How- 
ever, there is recent evidence against this argument (see Admati, DeMarzo, Hellwig, and Pfleiderer (2010)). An alternative explanation is that too much equity capital runs counter to the essential roles of the bank as an asset transformer and liquidity provider. Regardless, the key point for the purpose of this paper has already been established: banks must maintain some specified level of economic capital to serve as a buffer against distress. For any "acceptable" level of default probability, the model provides the technology to determine the how much additional economic capital is needed for controlling bank risk and maintaining solvency without being excessively deleterious to the bank's core functions.

Lastly, one may make the objection that a bank holding excessive amounts of cash on the balance sheet for an extended period of time would be counterproductive. First of all, in practice it need not be tied up in cash but could be used to purchase Treasury securities or other very low risk, highly liquid instruments. Furthermore, it is important to remember that at this point the model is just being proposed in an abstract manner without the presence of market frictions including transaction costs. With that being said, once the bank's default risk falls back down to acceptable levels that same cash can be used to purchase risky assets or make new loans. This allows the bank to grow its balance sheet in a safe and measured manner. In the empirical portion of the paper, some of the issues that may arise in the actual implementation of the model will be addressed.

\section{Data and Methodology}

\subsection{Description of Sample}

The empirical study looks at the top 15 American bank holding companies (BHCs) in terms of assets. The sample period covers from 2005:Q1 to 2008:Q4; this was a very interesting time for large banks in the US as it captures the transition from great prosperity to the most dramatic and devastating crisis since the Great Depression. The sample BHCs along with their average assets over the sample period are reported 
in Table 1. The first column lists the BHC name, which is then followed by the average assets in thousands of dollars. The last two columns contain the unique identifiers for the BHCs: the RSSD is the code assigned by the Federal Reserve to all financial institutions and their subsidiaries (and is also the lookup variable for the Bank Holding Company Database (BHCDB) in WRDS) and the PERMCO is the permanent company identifier for CRSP. This mapping was used to link the two datasets, which will be described in more detail below. It is important to note that these are, in fact, the largest BHCs in the country: the average assets over the sample period are at or above $\$ 100$ Billion. The "smallest" bank in the sample is KeyCorp with average assets of over $\$ 97$ Billion. This is significantly larger than the next bank, which would have been Northern Trust Corporation (RSSD 1199611). With just under \$66Billion in average assets Northern Trust falls short of KeyCorp's average assets by more than $\$ 30$ Billion.

The selection procedure had to be carefully designed so as to capture the most representative sample of the largest BHCs in America. The first step was to collect the Year End Consolidated Assets from the BHC Peer Group Average Reports for 2005, 2006, 2007, and 2008. The Peer Group Average Reports summarize key performance metrics and ratios for BHC Peer Groups. The Peer Groups consist of six different categories based on BHC characteristics, and the reports provide a benchmark for analyzing and comparing a bank to others with similar traits. The first five Peer Groups are by asset size (Peer Group 1 is for BHCs with total assets greater than or equal to $\$ 10$ billion; Peer Group 5 is for BHCs with less than $\$ 500$ million in assets). The last one, Peer Group 9, is reserved for "atypical banks". ${ }^{25}$ As it turns out, some of the BHCs in Peer Group 9 happen to be large institutions (in terms of asset size) that are relevant to the study; two particular examples being MetLife and PNC Financial Services Group. The sample therefore was restricted to just Peer Group 1 and Peer Group 9.

\footnotetext{
${ }^{25}$ The specific criteria for being categorized in Peer Group 9 can be found in the User's Guide for the Bank Holding Company Performance Report available from the Board of Governors of the Federal Reserve System.
} 
For each BHC in Peer Group 1 and Peer Group 9 the average assets were computed for 2005 to 2008. Several requirements were imposed to ensure a consistent and comprehensive data set. First, each BHC had to have four consecutive observations in the BHCDB; i.e. assets reported for December 2005, December 2006, December 2007, and December 2008. Then, each BHC had to be in the "matched sample", which means that the following two conditions must be met. The BHC had to be a FR Y-9C reporter, as identified by the RSSD number (the FR Y-9C reports will be discussed in the next subsection) and the BHC must be publically traded and have continuous stock price data in CRSP over the sample period (1259 stock price observations).

There are a few things to be said about the landscape of the banking industry during the sample period and how they are accounted for in this study. First, and perhaps most notable in the context of this study, is the 2007 merger between Bank of New York (RSSD 1033470) and Mellon Financial (RSSD 1068762) to form the BHC Bank of New York Mellon (RSSD 3587146). Both the predecessor firm, Bank of New York, and the merged firm, Bank of New York Mellon, have the same PERMCO in CRSP allowing for a consistent time series of stock prices. Due to the fact that Mellon Financial is not in CRSP and, in the years prior to the merger, Bank of New York was more than twice the size of Mellon financial (in terms of assets), Bank of New York is used for 2005 and 2006.

Also, Wachovia Corporation (RSSD 1073551) was acquired by Wells Fargo (RSSD 1120754) in 2008. However, since there is not data for the entire sample period, Wachovia is not included in the analysis whereas Wells Fargo is; the RSSD and PERMCO for Wells Fargo are consistent for the entire sample period. Lastly, Washington $\mathrm{Mu}-$ tual Bank failed in 2008. The assets were ultimately sold off to JP Morgan Chase.

\subsection{Data}

Most of the data for this study comes from the FR Y-9C reports, which are submitted quarterly to the Federal Reserve by all bank holding companies (BHCs) with 
consolidated assets of $\$ 500$ million or more. The FR Y-9C reports contain very detailed information about the income and condition of bank holding companies, and are intended to parallel the Call Reports, which are submitted to the FDIC by commercial banks. The difference is that the Call Reports are at the individual bank level rather than the holding company level; as such, there can be (and usually are) multiple entities that role up into the BHC. The two reports do not reconcile even when aggregated due to non-commercial bank subsidiaries that are included in the consolidated figures for the BHCs. Since this study deals with BHCs, the FR Y-9C reports are the most appropriate source for the bank-specific data needed.

The FR Y-9C reports summarize the bank's operations in two sections. First is the "Consolidated Report of Income", Schedule HI, which lists all income, expenses, and accruals, as well as net charge-offs and recoveries on bad loans over a particular quarter. A breakdown of the components of and changes in the BHC equity capital are given in Schedule HI-A. Details regarding the loan loss reserve, including charge-offs and recoveries, are given in Schedule HI-B. Then there is the "Consolidated Balance Sheet", Schedule HC, which gives a snapshot of the bank's assets, liabilities, and capital position as of quarter-end. The multitude of supporting sections (Schedule HC-B to HC-S) allow for a much more detailed look at the condition of the BHC.

While most of the data used in this study comes from Schedule HC, some of the more detailed information was used to supplement the basic line items from the balance sheet. Two sections were particularly useful: Schedule HC-M was used to disentangle the appropriate seniority for some ambiguous liabilities and Schedule HC$\mathrm{R}$ was used to define and properly identify the components of regulatory capital.

Line Item \#16 in Schedule HC is for "Other Borrowed Money", which is not entirely clear as to these liabilities' position in the seniority structure. However, within Schedule HC-M this "Other Borrowed Money" is further broken down into commercial paper, borrowed money not reported elsewhere that is due within one year, and other borrowed money with more than one year left to maturity. Commercial paper (Line Item \#14(a) in Schedule HC-M) is included in the data as short-term, senior debt. Line Item \#14(b) in Schedule HC-M is other borrowed money that is not re- 
ported elsewhere and due within one year. This item is also included the data under short-term, senior debt. It contains repurchase agreements with original maturity of more than one day, transfers of financial assets not considered 'sales', funds borrowed from Federal Reserve Banks with maturities under one year, and term federal funds purchased, among others. The last component of "Other Borrowed Money" (Line Item \#14(c)) consists of long-term borrowing not reported elsewhere, including mortgages on fixed assets, capital leases, as well as unsecured perpetual debt that are not subordinated. In most cases this item is an insignificant portion of the BHC total liabilities, and is therefore not included in the data.

In addition, Schedule HC-R contains a detailed breakdown of risk-based regulatory capital. Recall, that as per Basel II there are two forms of regulatory capital: Tier 1 and Tier 2 capital. Tier 1 capital is predominantly comprised of shareholders' equity plus or minus various adjustments for unrealized and accumulated gains or losses. In addition to common stock and perpetual preferred stock, limited amounts of other qualifying claims are permitted in the calculation of Tier 1 capital. Tier 2 capital includes qualifying subordinated debt, redeemable preferred stock, trust preferred securities, and perpetual preferred stock that was not included in Tier 1 capital.

The actual FR Y-9C reports are available from the National Information Center website at http://www.ffiec.gov/nicpubweb/nicweb/NicHome.aspx. The RSSD ID can be used to search for the specific Bank Holding Company's records and then the FR Y-9C report can be accessed for any given quarter going back several years. The FR Y-9C data can also be downloaded from the Bank Holding Company Database (BHCDB) in WRDS. This has the added benefit that FR Y-9C data can be downloaded for multiple quarters and/or multiple BHCs in one pass. However, the downside is that the data items are not clearly defined within the BHCDB and so one must still use the actual FR Y-9C report to create a mapping of the the variable code to the data item. Table 2 shows all of the data items that were used in the analysis. The table lists the data items, the source, and the variable code. In addition to the BHCDB, CRSP and Compustat were used to obtain market data and some supplementary financial statement data for the banks in the sample. 
Table 2 can be used to show how the model inputs and other relevant metrics were created from the BHCDB downloads. The sum of Item 1 through Item 4 gives the total deposits. Adding Total Deposits with Federal Funds Purchased (Item 5), Repurchase Agreements (Item 6), Commercial Paper (Item 7), and Other Borrowed Money with remaining maturity of 1 year or less (Item 8) gives the face value of the shortterm, senior debt or $F_{1}$ in the model. The face value of the long-term, junior debt is taken to be the sum of Item 9 and Item 10, Subordinated Notes and Debentures and Trust Preferred Securities, respectively; this is $F_{2}$ in the model. Another important quantity computed from the BHCDB downloads is the Risk-Based-Regulatory Capital Ratio (RBRC Ratio). This is Tier 1 Capital (Item 11) divided by the Total Risk-Weighted Assets (Item 12). The market value of the bank's equity is obtained from CRSP and is Stock Price (Item 13) multiplied by Shares Outstanding (Item 14). This and equity volatility, which is computed as the three-month rolling standard deviation of daily log-price-relatives times the square root of 252 , are the two primary market inputs. ${ }^{26}$

Finally, the risk-free rate data is from the Federal Reserve Bank of St. Louis FRED database. The one year Constant Maturity Treasury (CMT) yield was retrieved for every month over the sample period; the data point for the last day of each quarter was then pulled in to serve as the risk-free rate in the model. Monthly yields were downloaded from the FRED database and then matched to the FR Y-9C reports by date.

\subsection{Methodology}

This subsection covers the methodology behind running the model. First, the model inputs are specified. This is followed by a discussion about calibration of the model, where an iterative procedure is used to solve two equations in two unknowns. Finally, the model outputs are reviewed with emphasis being placed on two specific measures that are relevant for the analysis of bank capital.

\footnotetext{
${ }^{26}$ In symbols: $\sigma_{E}=\frac{s d}{\sqrt{1 / 252}}=s d \sqrt{252}$, where $s d$ is the standard deviation of $\ln \frac{P_{t}}{P_{t-1}}$ for each day over the previous three months.
} 
As mentioned earlier in the paper, the model uses both market information and the liability structure of the bank in question. At this point only equity market information is considered; the reason being that every public bank holding company has traded equity with market information readily available and accessible. Specifically, the market information that is used as inputs into the model are the market value of the bank's equity and the equity volatility, both defined in terms of the data above. For any time $t$ these quantities are denoted as $E_{t}$ and $\sigma_{E}$, respectively. Recall that $E_{t}$ is the value of the compound call option on the bank's assets, which is known in closed-form as a function of the bank's asset value and asset volatility. Since the market value of equity and equity volatility are observable, but the true market value of the bank's assets and asset volatility are unobservable there is something of an inverse problem. Fortunately, the model allows for this problem to be solved rather easily (calibrated using a numerical algorithm as discussed below) and the solution provides some insight about the implied market value of the bank's assets at any given time. The other required inputs to the model are from the bank's liability structure. First, is a measure of the face value of the short-term, senior debt that is outstanding at a particular point in time. This amount, $F_{1}$, will serve as the first strike price in the dynamic compound option model. The next input is the face value of the long-term, junior debt. This amount, $F_{2}$, is the sum of the outstanding subordinated notes and debentures and trust preferred securities as described in the previous subsection. $F_{2}$ is therefore the second strike price in the dynamic compound option model. The endogenous default boundary is, in fact, explicitly a function of the values of these inputs $F_{1}$ and $F_{2}$. The model also requires as inputs the average maturities of the outstanding short-term, senior debt and the long-term, junior debt; $T_{1}$ and $T_{2}$, respectively. Due to data constraints, this study assumes $T_{1}=1$ and $T_{2}=20$, which implies that the average maturity of the short-term, senior debt is one year and the average maturity of the long-term, junior debt is 20 years. Regulators and internal risk managers could have access to data that can allow for more precise estimation of the average maturity of the debt obligations thereby allowing for more accurate 
estimation of default probabilities. The last input is the appropriate risk-free rate. ${ }^{27}$ In the empirical implementation of the model the risk-free rate is set equal to the one year Constant Maturity Treasury (CMT) yield at the same point in time as the FR Y-9C report (i.e. 04-01-2005 for the end of 2005:Q1).

Once the inputs are obtained, the model must be calibrated. The calibration is necessary because the closed-form solution gives the value of an observable market value (equity) but all of the outputs are in terms of an unobservable quantity: the market value of the bank's assets. At any given time $t$, the observable equity value and equity volatility, $E_{t}$ and $\sigma_{E}$, are related to the unobservable asset value and asset volatility, $V_{t}$ and $\sigma_{E}$, by Equation (3) and Equation (10). Let $E\left(V_{t}, \sigma_{V}\right)$ refer to the closed-form expression in Equation (3). ${ }^{28}$ Also let $\sigma_{E}\left(V_{t}, \sigma_{V}, E_{t}\right)$ refer to the expression relating equity volatility to asset volatility given in Equation (10). The goal is to simultaneously solve for $V_{t}$ and $\sigma_{V}$ in the following set of equations:

$$
\begin{gathered}
E\left(V_{t}, \sigma_{V}\right)=\text { Equity } \\
\sigma_{E}\left(V_{t}, \sigma_{V}, E_{t}\right)=\text { Volatility }
\end{gathered}
$$

where Equity is the market value of equity as computed from the data (Stock Price times Shares Outstanding)and Volatility is the standard deviation of the daily logprice-relatives multiplied by the square root of 252 (see the end of Section 4.2). For each quarter in the sample period there are 15 values of Equity and Volatility corresponding to each of the BHCs in the sample. The iterative procedure to solve for $V_{t}$ and $\sigma_{V}$ is therefore run for each of the 240 observations (15 BHCs times 16 quarters) to calibrate the model to the market data.

\footnotetext{
${ }^{27}$ This results in risk-neutral default probabilities. In order to compute the "true" probabilities under the physical measure, one would have to be able to accurately estimate the risk premium for each bank holding company over the course of the entire sample period. The cost of attempting to incorporate this into the model arguably outweighs the benefits, since it can be shown (mathematically) when the risk premium is non-negative, the risk-neutral default probability will serve as an upper bound on the physical default probability. This will result in more conservative estimates of default probabilities and capital requirements, which is not necessarily a bad thing.

${ }^{28}$ In the interest of brevity, the other model inputs $-F_{1}, F_{2}, T_{1}, T_{2}$, and $r$-have been dropped from the expression.
} 
For each BHC-quarter the iterative procedure goes as follows. First, the initial values are set as $V_{0}=$ Assets and $\sigma_{V^{0}}=$ Volatility $*\left(\frac{\text { Liabilities }}{\text { Assets }}\right)$, where Assets and Liabilities are the book values of total assets and total liabilities, respectively, from the bank's balance sheet; Volatility is the estimated equity volatility as described in the previous paragraph. Then, $V_{t}$ is numerically solved so that Equation (22) is satisfied. Although the compound call value computed by Equation (3) will equal the current market value of the bank's equity, the value of $\sigma_{E}$ will change as per Equation (10). Consequently, $\sigma_{V}$ must then be numerically solved so that Equation (23) is satisfied. This causes the compound call as a function of the asset value and new asset volatility to deviate from the market value of equity, so the procedure must be repeated until the results converge. Fortunately, convergence is relatively quick.

Once the conditions given by Equation (22) and Equation (23) are satisfied for all 240 of the BHC-quarters, the model outputs can be used for analysis. There are many outputs from the model: short-term default probabilities, forward default probabilities, total survival probability, equity delta, implied market value of assets, market value of junior debt, market value of senior debt (discount to par), etc. However, there are two outputs that are particularly valuable for this study. The first is the short-term default probability which is computed in closed-form and given by Equation (??). Since the short-term default probability takes the entire liability structure into account (it depends on $F_{1}, F_{2}, T_{1}$, and $T_{2}$ ) and it is a function of the endogenous default boundary $(\bar{V})$, this is the key output and metric that should be used in determining the appropriate capital requirements. Recall, the objective of the model user (bank regulator or internal risk manager) is to find the minimum amount of capital needed to ensure that the bank will be able to fund and repay the pending debt obligations, considering the size and timing of all future promised payments to creditors. It is, therefore, of utmost importance to know the likelihood that the most imminent obligations will be satisfied. Then, if the short-term default probability is unacceptably high, the model can be used to solve for how much capital should be added to reduce the probability to a more comfortable level. 
In addition to the short-term default probability, the model produces an output that is a useful metric for quantifying the economic capital of a bank within the context of the model. This is the Model-Implied Economic Capital ratio (MIEC_Ratio) given earlier in Equation (18).

Some will argue that using market values in the management of bank capital will introduce too much noise into the process. It should be noted that the MIEC ratios are not necessarily proposed to be used in lieu of RBRC ratios but rather in conjunction with the existing measures of bank capital. As will be shown in the next section, when both the MIEC ratio and the RBRC ratio are analyzed with respect to one another there are many interesting patterns that can be identified. Furthermore, the MIEC ratios are not as prone to manipulation or regulatory arbitrage and they provide a way to integrate market discipline into the management and oversight of bank capital.

\section{$5 \quad$ Empirical Results and Analysis}

After the model was run for all 15 BHCs over the 16 quarter sample period, yielding 240 data points for each output, the results were averaged cross-sectionally. This allows for more general, high-level analysis of the average condition of the largest BHCs both before and during the Financial Crisis. The time-series of cross-sectional averages (default probabilities, capital ratios, etc.) are reported and examined to get a "big picture" perspective of the condition of the largest banks in the financial system over the sample period. The model illustrates that existing regulatory measures fell short precisely when conditions began to really deteriorate in the financial system. At the end of the section a more in-depth analysis is performed on the individual BHC capital positions at the height of the Financial Crisis.

The starting point in analyzing the results is the short-term default probabilities. Recall, that these are the most important output regarding the health of the financial institution in question. The short-term default probabilities are, by definition, forward-looking and take the entire liability structure into account. Hence, 
they provide an objective, quantitative measure of the solvency of the financial institution using the most recent and relevant information. Taking the cross-sectional average across the $15 \mathrm{BHCs}$ in the sample gives rise to a time-series of default probabilities. Figure 3 plots this time-series of average short-term default probabilities over the sample period. It is interesting to see that short-term default probabilities for the 15 largest BHCs were close to zero up until the latter half of 2007. This is when the infamous "subprime crisis" began to incite panic throughout the country. ${ }^{29}$ Then, throughout 2008, when the full-blown financial crisis permeated the entire financial system, bank default probabilities climbed consistently and aggressively. By December 2008, when the sample period ends, average short-term default probabilities spiked at almost 50\%. A crude interpretation of this result is that, on average, the probability that one of the nation's largest banks would fail within one year was akin to flipping a fair coin!

The model uses market information, namely equity values and volatility, along with each BHC's liability structure to compute the default probabilities and implied market value capital ratios. As such, it must be the case that any changes in the market value capital ratios over time are going to come from changes in one or more of those factors: changes in the market's perception of value, the degree of uncertainty, and/or the mix of short-term and long-term debt in the bank's financing. Intuition suggests that the market value capital ratios should be negatively correlated with short-term default probabilities, especially considering that they are both generated by the same structural credit risk model.

Figure 4 shows the correlations between the short-term default probabilities and the market value capital ratios for each $\mathrm{BHC}$ in the sample. All but one $\mathrm{BHC}$ exhibit high negative correlations between these two metrics. The lone BHC with a positive correlation is MetLife (MET), with correlation of approximately $65 \%$. By drilling down and looking at the data for MetLife more carefully, it can be seen that a spike in MetLife's short-term default probabilities late in 2008 comes purely from

\footnotetext{
${ }^{29}$ See Crouhy, Jarrow, and Turnbull (2008) and Gorton (2009) for excellent accounts of the causes and extreme ramifications of the "subprime crisis".
} 
volatility. The market value of equity dropped but the implied market value of assets fell by proportionately more; and at the same time, the total face value of MetLife's senior, short-term debt obligations $\left(F_{1}\right)$ was reduced indicating some de-leveraging over this period. Meanwhile equity volatility for MET almost doubled from 2008:Q3 to 2008:Q4. Thus, it can be concluded that the large increase in MetLife's short-term default probabilities was a result of widespread uncertainty about large financial institutions. This shows how a particular anomaly in the results can be explained by looking at which of the factors (i.e. model inputs) are behind it.

The Model-Implied Economic Capital (MIEC) ratios are computed as follows. For each quarter the market value of equity is observed. The MIEC ratio would be equal to this quantity divided by the market value of the bank's assets. However, as noted earlier, the market value of bank assets are unobservable. Fortunately, by solving two equations in two unknowns, the structural credit risk model gives the implied market value of the assets, conditional upon the market information and liability structure. ${ }^{30}$ Thus, the MIEC ratio, is computed by dividing the market value of the BHC's equity $\left(E_{t}\right)$ by the model-implied asset value $\left(V_{t}\right)$. The Risk-Based Regulatory Capital ratio, or RBRC ratio, is computed directly from the FR Y-9C data. It is, in fact, the "core capital" ratio which is Tier 1 Capital divided by Total Risk-Weighted Assets.

From Figure 5, it can be seen that on average, the MIEC ratios of the BHCs declined while the RBRC ratios stayed fairly constant, and even increased slightly, over the sample period. This pattern actually has some very profound regulatory implications. When there is convergence in the MIEC and RBRC ratios, there are two [not mutually exclusive] conclusions that one may draw: the condition of the bank in question has deteriorated so severely that the market value of its common equity has fallen to levels such that it is in line with the book value of core capital relative to their respective measures of assets and/or the RBC ratios have been manipulated so as to give off the impression that the bank is healthier than it really is. The most convenient way to manipulate the RBC ratio is by moving some risky assets off of the balance sheet, in a type of "regulatory capital arbitrage".

\footnotetext{
${ }^{30}$ This iterative procedure was described above in Section 4.3.
} 
It is rather alarming to see that while the RBRC ratios hovered around $8 \%$ to $9 \%$, which by regulatory standards is "well-capitalized", the MIEC ratios declined steadily from well over $20 \%$ to half of their highest levels. As pointed out above, these results can be coming from one of three primary factors: decreasing valuations (the market value of equity will decrease by more, in relative terms, and at a faster rate than the market value of the assets, from convexity in the compound call option value), increasing volatility, and/or increasing leverage. This last factor (increasing leverage) can be ruled out simply by looking at the BHCs' leverage ratios and noting that, on average, there was very little variation in the degree of leverage over the sample period. Figure 6 plots four different measures of leverage using the collected data. Again, the reported ratios are cross-sectional averages from the 15 BHCs, to obtain a time series of leverage ratios over the sample period. The first ratio (TL/TA) is total liabilities over total assets, which captures the overall degree of leverage for the banks. This ratio remained very constant at about 0.9 over the sample period. The next ratio (Dep/TA) is total deposits over total assets, which shows the extent to which the banks rely on traditional deposits as a source of funding. Although there was more variation in the ratio of total deposits to assets, this measure of leverage was still fairly constant over the sample period staying between 0.5 and 0.6. The last two ratios ( $\mathrm{Sr} / \mathrm{TA}$ and $\mathrm{Jr} / \mathrm{TA}$ ) show the amount of senior debt and junior debt, respectively, as percentages of total assets. As would be expected for a financial institution, a greater proportion of the banks' debt funding comes from the shortterm, senior debt as opposed to the long-term, junior debt. Both of these ratios are also quite stable on average for the 15 BHCs.

Since leverage ratios remained fairly constant for the sample BHCs over this period, that can be ruled out as a factor for the declining MIEC ratios. Rather, the falling MIEC ratios can be attributed to a complex mix of increasing volatility and decreasing market valuations. This is evidence of market discipline at work and could potentially have provided a good opportunity for regulators and market participants to unite in combating the financial crisis. 
The third quarter of 2008 (2008:Q3) represents the first point in the sample period where all 15 BHCs had short-term default probabilities above $10 \%$. While this might be a bit alarming it is not surprising. It was during this time that Lehman Brothers failed, AIG had to be bailed-out, Fannie Mae and Freddie Mac went into conservatorship, and the Troubled Asset Relief Program (TARP) was announced. Since all 15 BHCs exhibited elevated short-term default probabilities, 2008:Q3 provides a valuable opportunity to examine the individual bank capital positions in the sample and to implement the model to solve for the economic capital deficiency (ECD) as described in Section 3.6. It should be noted that the decision to set $\alpha=5 \%$ is somewhat arbitrary; the same procedure can be done to obtain results for different $\alpha$-levels. Also, it is important to reiterate that the "helicopter drop" approach is used in that no claim is made about where the capital should come from. This is left open for future research. The goal here is to determine how much economic capital each BHC should have had in 2008:Q3 to keep default risk under control. Finally, it is assumed that the hypothetical capital infusion is in the form of cash. Since cash has zero volatility there are two effects on the bank: first, asset values increase and, second, the weighted-average asset volatility decreases. The relationship is highly nonlinear, which is captured by the model.

Figure 7 plots the ECDs as computed by the model. To control for size the results are scaled by the book value of assets. The banks are presented in size order (book value of assets as of 2008), going from largest to smallest on the x-axis. The model results are given by the dark, solid bar. For each bank the model results are compared to three other numbers. The first is the amount of TARP funds received by each $\mathrm{BHC}$ at the end of 2008; if the BHC did not receive any TARP funds, then this number is zero. The second number is the result of the Supervisory Capital Assessment Program (SCAP), better known as the "stress tests" conducted by the Federal Reserve Board of Governors in early 2009. The SCAP results indicated how much capital was needed by each BHC at the end of 2008 according to macroeconomic simulations, pro-forma forecasting, and the existing risk-based capital requirements. All 15 BHCs in the sample were included in the SCAP stress tests. The "SCAP 
Buffer" that was reported in the press was the amount of capital needed at the end of 2008 as indicated by the stress tests less any capital actions taken in the first part of 2009. The numbers used to construct Figure 7, and in the resulting analysis, are the amounts before accounting for any capital actions; this allows the comparisons to be consistent- i.e. the amount of capital needed at the end of 2008. The last number is the sum of the TARP and SCAP amounts.

Figure 7 shows the full sample of all 15 BHCs. According to the model, all but one BHC needed more capital than TARP and SCAP combined. The model indicated that PNC Financial Services Group actually needed less capital than the sum of TARP and SCAP; in fact, the model estimate is very close to what was distributed to the bank through TARP. However, the other 14 BHCs seem to have still been undercapitalized even after the programs that were set up to restore financial system stability. This could help explain why the Financial Crisis persisted for so long, even after the very costly government intervention, and why the economy did not experience the $\mathrm{V}$-shaped recovery that so many predicted.

There are two outliers in the sample: Regions Financial and Fifth-Third Bancorp. The results imply that these two BHCs should have had over $40 \%$ of the balance sheet as cash. This is completely unrealistic and even counterproductive for any bank, especially in times of distress. What that says, however, is that clearly something else was going on with these particular BHCs. Extreme results such as these should be interpreted as evidence that a wider variety of tools, in addition to managing capital, would have to be used to alleviate the financial distress for such a bank (perhaps asset sales). Even though the capital estimates may be hard to justify for these extreme cases, the model is still useful in identifying sever problem banks. The case-in-point: these two BHCs, Regions Financial and Fifth-Third Bancorp, were two of the worst performers throughout the first half of 2009 with their stock prices falling to as low as $65 \%$ and $86 \%$ of the 2008 year-end levels, respectively. Figure 8 shows the restricted sample with the two outliers removed, and puts the capital needs of the remaining BHCs in better perspective. Again the banks are presented in size order, going from largest to smallest on the $\mathrm{x}$-axis. This shows that the proportion of capital that was 
needed by the sample BHCs is independent of size. However, in absolute terms, this means that the larger banks needed more economic capital (in dollar amounts) several orders of magnitude higher than the smaller banks.

\section{Conclusion}

This paper proposed the use of a structural credit risk model to analyze the economic capital of banks. The approach has many features that make it attractive relative to the existing methods for determining the amount of economic capital needed by financial institutions during both crisis and non-crisis times. First, the structural credit risk model takes both sides of the balance sheet into account: both the asset risk and the liability structure (both in terms of maturity and seniority). The prevailing paradigm focuses on asset risk and practically ignores the liability structure. Second, the model uses market information and, by definition, is forward-looking. This is in contrast to the existing static measures that use historical data. Third, the model has endogenous default which is a critical feature in determining the amount of capital needed by a financial institution. The model yields several useful metrics for evaluating the solvency and economic capital of financial institutions including the Model-Implied Economic Capital (MIEC) Ratio. It was also shown that the driving force behind the analysis of economic capital for financial institutions is the short-term default probability. Although this may seem like a myopic approach for risk management of banks it is quite the opposite. The short-term default probability computed by the model contains all relevant information including asset risk, endogenous default, and the complete liability structure - i.e. it is a function of not

only the amount of debt in the capital structure, but the mix of short-term versus long-term debt in funding the bank's operations.

The model gives rise to many interesting insights about financial institutions, both theoretically and empirically during the recent Financial Crisis. The model captures the complex, nonlinear relationship between volatility, default probabilities, and bank capital. The Model-Implied Economic Capital (MIEC) ratios can be compared with 
the Risk-Based Regulatory Capital (RBRC) ratios to identify patterns indicating that a bank might be on the verge of distress and can also identify distress in the entire banking system. Finally, the model can be used to compute the economic capital deficiency (ECD) which is the additional amount of capital needed to bring short-term default probabilities below a specified acceptable level.

The model does not allow for asset sales, which could be one additional tool that a distressed bank could use when undercapitalized and in the midst of a crisis. However, the risk of fire sales and liquidity spirals arises. Again, these are beyond the scope of the current model. The model could potentially be expanded to incorporate market frictions such as liquidity, explicit distress costs, and asymmetric information. However, the inclusion of any one of these market frictions would be extremely nontrivial and it was shown that, even in this primitive form, the model provides significant insight into the management and analysis of bank capital positions. 


\section{References}

Acharya, Viral V., Douglas Gale, and Tanju Yorulmazer, 2010, Rollover risk and market freezes, NBER Working Papers.

Admati, Anat R., Peter M. DeMarzo, Martin F. Hellwig, and Paul Pfleiderer, 2010, Fallacies, irrelevant facts, and myths in the discussion of capital regulation: Why bank equity is not expensive, Stanford GSB Research Paper No. 2063.

Adrian, Tobias, and Hyun Song Shin, 2010, Liquidity and leverage, Journal of Financial Intermediation 19, 418-437.

Allen, Linda, and Anthony Saunders, 1993, Forbearance and valuation of deposit insurance as a callable put, Journal of Banking and Finance 17, 629-643.

Altman, Edward I., and Anthony Saunders, 2001, An analysis and critique of the bis proposal on capital adequacy and ratings, Journal of Banking and Finance 25, 25-46.

Avery, Robert B., Terrence M. Belton, and Michael A. Goldberg, 1988, Market discipline in regulating bank risk: New evidence from the capital markets, Journal of Money, Credit and Banking 20, 597-610.

Basel Committee on Banking Supervision, 2011, Basel III definition of capital - Frequently asked questions, Bank for International Settlements.

Berger, Allen N., Sally M. Davies, and Mark J. Flannery, 2000, Comparing market and supervisory assessments of bank performance: Who knows what when?, Journal of Money, Credit, and Banking 32, 641-667.

Berkowitz, Jeremy, and James O'Brien, 2002, How accurate are value-at-risk models at commercial banks?, The Journal of Finance 57, 1093-1111.

Bessis, Jöel, 2010, Risk Management in Banking (John Wiley \& Sons) third edn.

Bharath, Sreedhar T., and Tyler Shumway, 2008, Forecasting Default with the Merton Distance to Default Model, Review of Financial Studies. 
Black, Fischer, and John C. Cox, 1976, Valuing corporate securities: Some effects of bond indenture provisions, Journal of Finance 31, 351-367.

Black, Fischer, and Myron Scholes, 1973, The pricing of options and corporate liabilities, Journal of Political Economy 81, 637-654.

Bliss, Robert R., and Mark J. Flannery, 2002, Market discipline in the governance of u.s. bank holding companies: Monitoring vs. influencing, European Finance Review $6,361-395$.

Chen, Ren-Raw, Xiaolin Cheng, Frank J. Fabozzi, and Bo Liu, 2008, An explicit, multi-factor credit default swap pricing model with correlated factors, Journal of Financial and Quantitative Analysis 43, 123-160.

Collin-Dufresne, Pierre, and Robert S. Goldstein, 2001, Do credit spreads reflect stationary leverage ratios?, Journal of Finance 56.

Cooperstein, Richard L., George G. Pennacchi, and F. Stevens Redburn, 1995, The aggregate cost of deposit insurance: A multiperiod analysis, Journal of Financial Intermediation 4, $242-271$.

Crosbie, Peter, and Jeff Bohn, 2003, Modeling default risk, Discussion paper, Moody's KMV.

Crouhy, Michel, Robert A. Jarrow, and Stuart M. Turnbull, 2008, The subprime credit crisis of 2007, The Journal of Derivatives 16, 1074-1240.

Delianedis, Gordon, and Robert Geske, 2003, Credit risk and risk neutral default probabilities: Information about rating migrations and defaults, in EFA $2003 A n$ nual Conference Paper No. 962.

Diamond, Douglas W., and Raghuram G. Rajan, 2000, A theory of bank capital, Journal of Finance 55, 2431-2465.

Flannery, Mark J., 1998, Using market information in prudential bank supervision: A review of the u.s. empirical evidence, Journal of Money, Credit, and Banking 30, $273-305$. 
— , Simon H. Kwan, and M. Nimalendran, 2004, Market evidence on the opaqueness of banking firms' assets, Journal of Financial Economics 71, 419-460.

Flannery, Mark J., and Sorin M. Sorescu, 1996, Evidence of bank market discipline in subordinated debenture yields: 1983-1991, Journal of Finance 51, 1347-1377.

Friedman, Milton, 1969, The Optimum Quantity of Money and Other Essays (Aldine Publishing Company, Chicago).

Froot, Kenneth A., and Jeremy C. Stein, 1998, Risk management, capital budgeting, and capital structure policy for financial institutions: an integrated approach, Journal of Financial Economics 47, 55-82.

Geske, Robert, 1977, The valuation of corporate liabilities as compound options, Journal of Financial and Quantitative Analysis 12.

— 1979, The valuation of compound options, Journal of Financial Economics $7,63-81$.

— , and H. E. Johnson, 1984, The valuation of corporate liabilities as compound options: A correction, Journal of Financial and Quantitative Analysis 19.

Gorton, Gary, 2009, The subprime panic, European Financial Management 15, 10-46.

— , and Anthony M. Santomero, 1990, Market discipline and bank subordinated debt, Journal of Money, Credit, and Banking 22, 119-128.

Hart, Oliver D., and Luigi Zingales, 2009, A new capital regulation for large financial institutions, Working Paper.

He, Zhiguo, and Wei Xiong, 2011, Rollover risk and credit risk, The Journal of Finance forthcoming.

Hendricks, Darryll, and Beverly Hirtle, 1997, Bank capital requirements for market risk: The internal models approach, Economic Policy Review (19320426) 3. 
James, Christopher, 1996, Raroc based capital budgeting and performance evaluation: A case study of bank capital allocation, Discussion Paper, 96-40 Wharton School Center for Financial Institutions, University of Pennsylvania.

Jarrow, Robert, 2007, A Critique of Revised Basel II, Journal of Financial Services Research 32, 1-16.

Jorion, Philippe, 2006, Value at Risk: The New Benchmark for Managing Financial Risk (McGraw-Hill) 3rd edn.

— , 2009, Risk management lessons from the credit crisis, European Financial Management 15, 923-933(11).

Kashyap, Anil K., Raghuram G. Rajan, and Jeremy C. Stein, 2008, Rethinking capital regulation, in Maintaining Stability in a Changing Financial System. Federal Reserve Bank of Kansas City.

Kashyap, Anil K., and Jeremy C. Stein, 2004, Cyclical Implications of the Basel II Capital Standards, Economic Perspectives 28.

Krainer, John, and Jose A. Lopez, 2004, Incorporating equity market information into supervisory monitoring models, Journal of Money, Credit and Banking 36, 1043-1067.

Kupiec, Paul, 2004, Estimating economic capital allocations for market and credit risk, The Journal of Risk 6, 11-29.

Kupiec, Paul H., 1999, Risk capital and VaR, Journal of Derivatives 7, 41-52.

Leland, Hayne E., 1994, Corporate debt value, bond covenants, and optimal capital structure, The Journal of Finance 49, 1213-1252.

— 2004, Predictions of default probabilities in structural models of debt, Journal of Investment Management 2.

— , 2009, Structural models and the credit crisis, in China International Conference in Finance. 
— , and Klaus Bjerre Toft, 1996, Optimal capital structure, endogenous bankruptcy, and the term structure of credit spreads, Journal of Finance 51, 9871019.

Longstaff, Francis A., and Eduardo S. Schwartz, 1995, A simple approach to valuing risky fixed and floating rate debt, The Journal of Finance 50, 789-819 Papers and Proceedings Fifty-Fifth Annual Meeting, American Finance, Association, Washington, D.C., January 6-8, 1995.

Marcus, Alan J., and Israel Shaked, 1984, The valuation of fdic deposit insurance using option-pricing estimates, Journal of Money, Credit and Banking 16, 446460.

Merton, Robert C., 1974, On the pricing of corporate debt: the risk structure of interest rates, Journal of Finance 29, 449-470.

- 1977, An analytic derivation of the cost of deposit insurance and loan guarantees, Journal of Banking and Finance 1, 3-11.

Morris, Stephen, and Hyun Song Shin, 2009, Illiquidity component of credit risk, Working Paper.

Pennacchi, George G., 1987a, Alternative forms of deposit insurance, Journal of Banking and Finance 11, 291-312.

— , 1987b, A reexamination of the over- (or under-) pricing of deposit insurance, Journal of Money, Credit and Banking 19, 340-360.

Ronn, Ehud I., and Avinash K. Verma, 1986, Pricing risk- adjusted deposit insurance: An option-based model, Journal of Finance 41, 871-895.

— 1989 , Risk-based capital adequacy standards for a sample of 43 major banks, Journal of Banking and Finance 13, 21-29.

Santos, Joao A. C., 2001, Bank capital regulation in contemporary banking theory: A review of the literature, Financial Markets, Institutions and Instruments 10, 41. 
Squam Lake Working Group, 2009, Reforming capital requirements for financial institutions, Discussion paper, Council on Foreign Relations.

Stoughton, Neal M., and Josef Zechner, 2007, Optimal capital allocation using RAROC and EVA, Journal of Financial Intermediation 16, 312 - 342.

Stulz, Rene M., 2008, Risk management failures: What are they and when do they happen?, Journal of Applied Corporate Finance 20, 39-48.

— 2010, Credit default swaps and the credit crisis, Journal of Economic Perspectives 24, 73-92.

Szegö, Giorgio, 2002, Measures of risk, Journal of Banking and Finance 26, 1253 1272.

Vasicek, Oldrich Alfons, 2002, The distribution of loan portfolio value, Risk.

Zaik, Edward, John Walter, Gabriela Retting, and Christopher James, 1996, RAROC at Bank of America: From Theory to Practice, Journal of Applied Corporate Finance 9, 83-93. 
Figure 1: A Simplified Balance Sheet for a Banking Firm

\begin{tabular}{|l|l|}
\hline \multicolumn{1}{|c|}{ Assets } & \multicolumn{1}{|c|}{ Liabilities \& Equity } \\
\hline Loans \& Investment Securities & Short-term, Senior debt \\
\cline { 2 - 2 } & Long-term, Subordinated debt \\
\cline { 2 - 2 } & Shareholders' Equity \\
\hline
\end{tabular}

Figure 1 shows a simplified balance sheet for a typical banking firm. On the asset side the bank has risky loans and investment securities. On the left-hand side of the balance sheet shows that these positions are financed by a mix of short-term, senior debt (including deposits and repurchase agreements) as well as long-term, subordinated debt, and equity capital. A proper structural model must account for the unique liability structure of even the "simplest" financial institutions. 

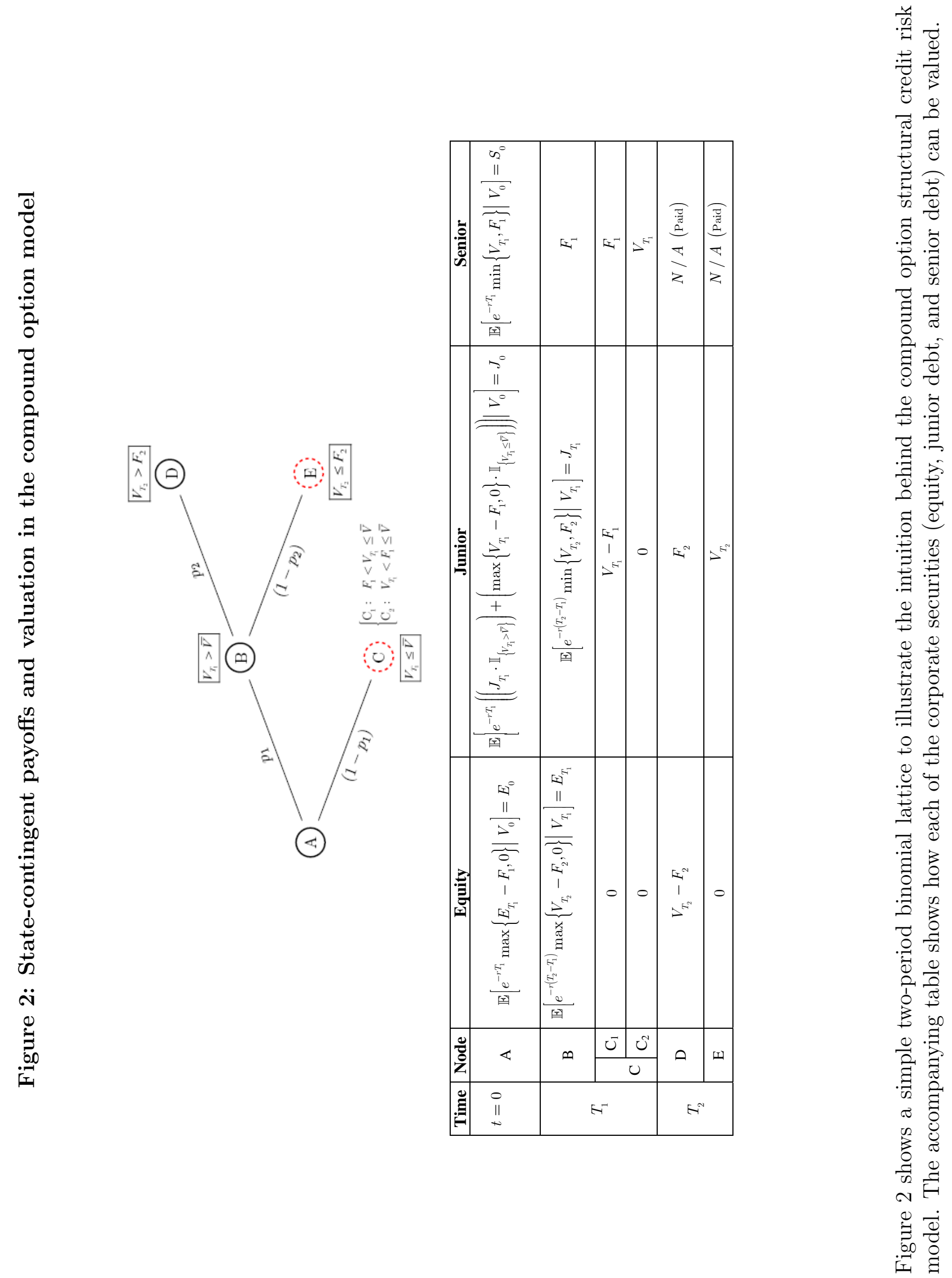


\section{Figure 3: Short-Term Default Probabilities}

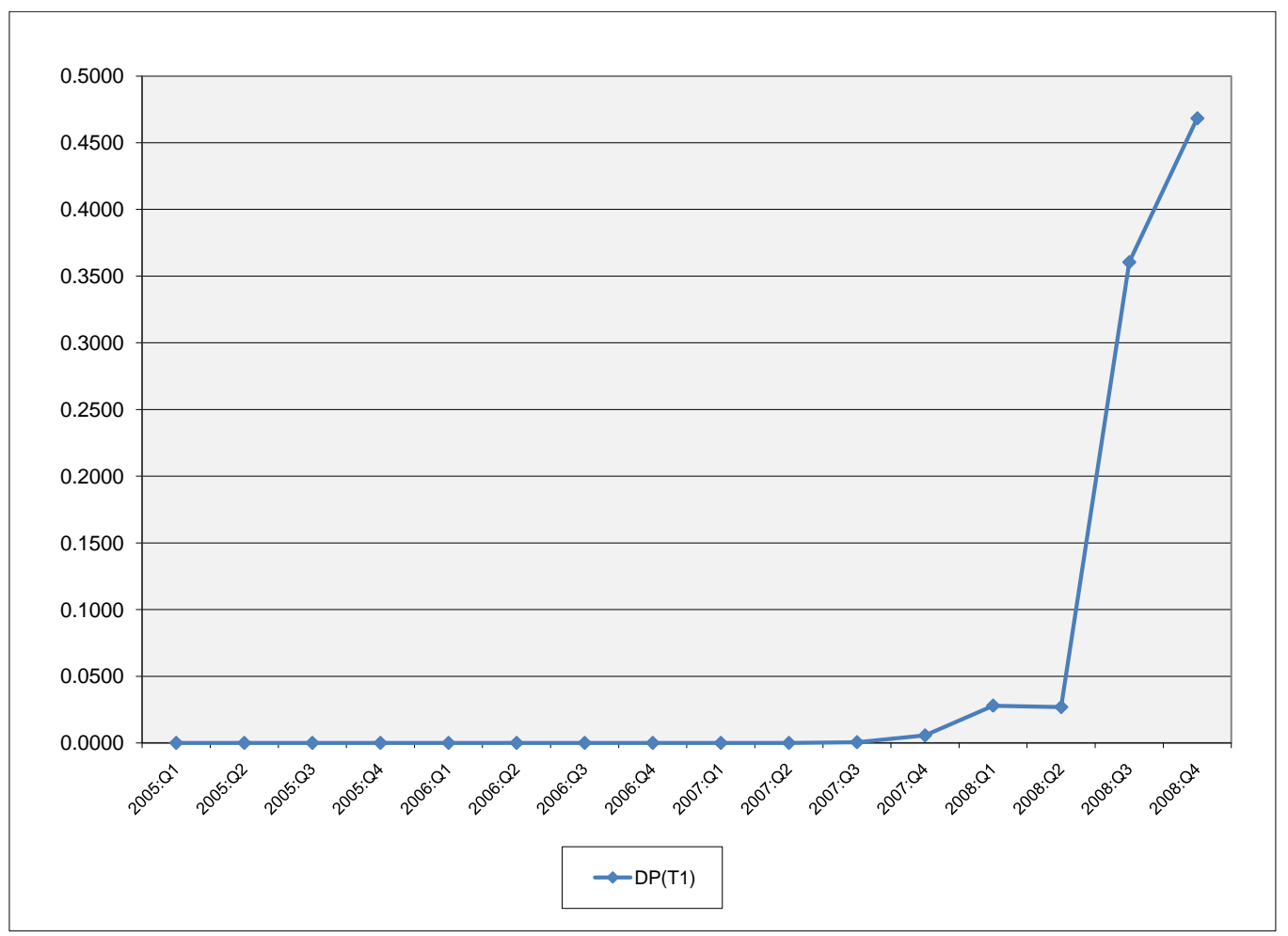

Figure 3 shows the short-term default probabilities computed by the model for the $15 \mathrm{BHCs}$ in the sample. The plot is of the cross-sectional average of the default probabilities and illustrates the evolution of the average market-implied default probabilities for the largest BHCs in America over the sample period. 


\section{Figure 4: Correlations Between Default Probability and Market Value Capital Ratios}

\begin{tabular}{|l|r|}
\hline \multicolumn{1}{|c|}{ BHC } & Corr(DP,MVC) \\
\hline BAC & -0.66677 \\
\hline BBT & -0.39779 \\
\hline BK & -0.80809 \\
\hline C & -0.63708 \\
\hline COF & -0.61549 \\
\hline FITB & -0.76529 \\
\hline JPM & -0.71587 \\
\hline KEY & -0.73381 \\
\hline MET & 0.65169 \\
\hline PNC & -0.79602 \\
\hline RF & -0.68269 \\
\hline STI & -0.69741 \\
\hline STT & -0.82793 \\
\hline USB & -0.63779 \\
\hline WFC & -0.64857 \\
\hline
\end{tabular}

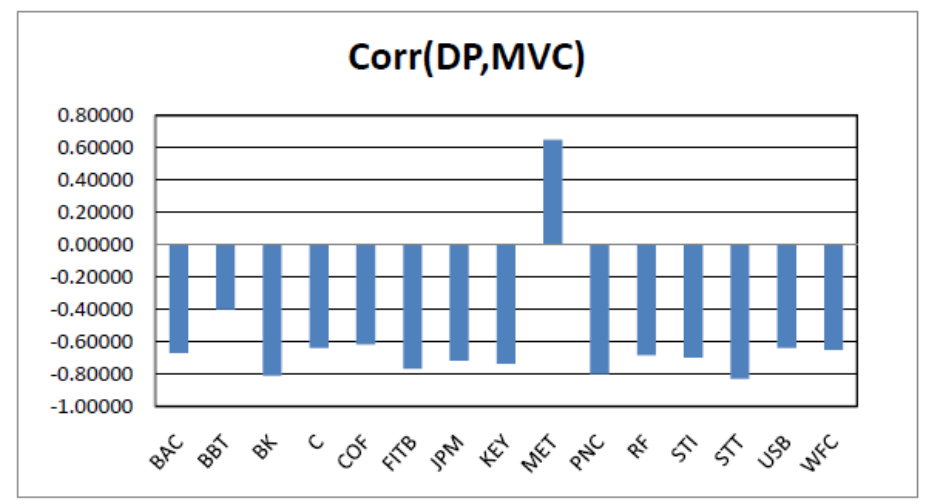

Figure 4 shows the correlations between short-term default probabilities and the market value capital ratios for the 15 BHCs in the sample. All but one BHC exhibits high negative correlation as predicted. The single positive correlation can be explained within the context of the Financial Crisis (see Section 5). 


\section{Figure 5: Capital Ratios}

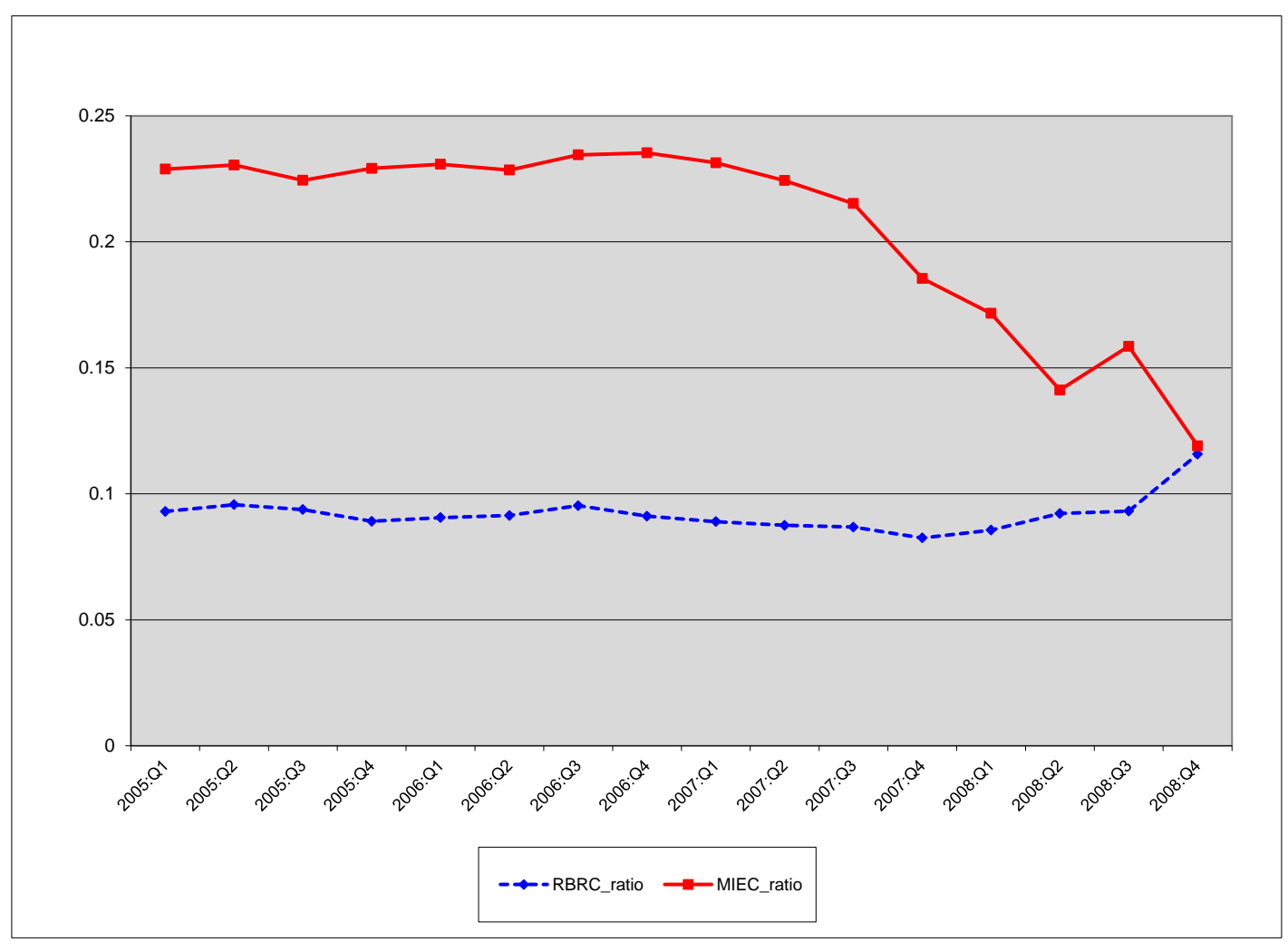

Figure 5 shows the Risk-Based Regulatory Capital (RBRC) ratios and ModelImplied Economic Capital (MIEC) ratios over the sample period. The plot shows the cross-sectional average of these ratios for the 15 BHCs in the sample. 
Figure 6: BHC Average Leverage

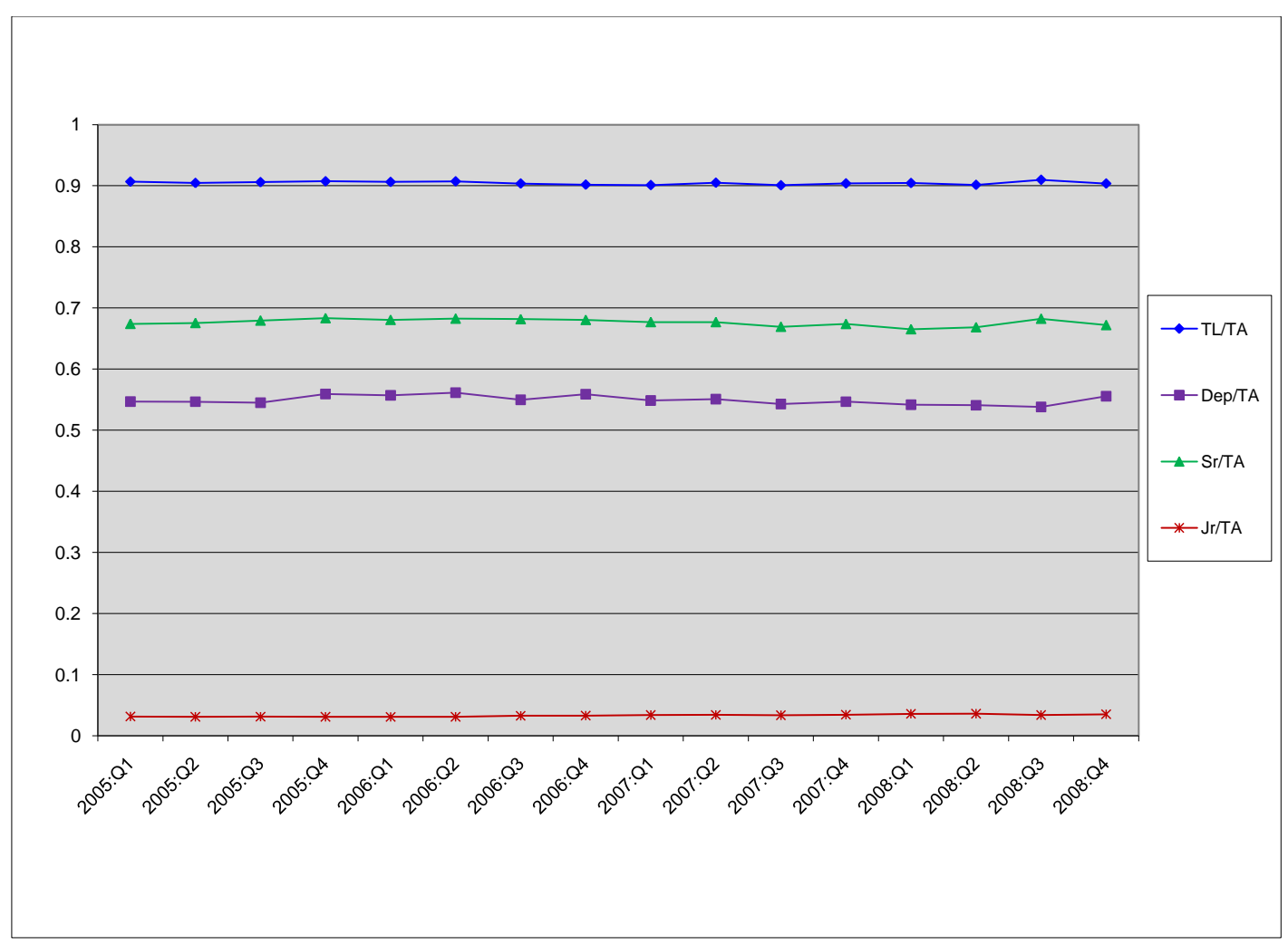

Figure 6 shows the cross-section averages of four different leverage measures for the 15 BHCs over the sample period. The first leverage measure (TL/TA) is the ratio of total liabilities to total assets. The second leverage measure (Dep/TA) is the ratio of deposits to total assets. The third measure $(\mathrm{Sr} / \mathrm{TA})$ is the ratio of senior debt to total assets. The last measure $(\mathrm{Jr} / \mathrm{TA})$ is the ratio of junior debt to total assets. It is not surprising that deposits and other short-term, senior debt claims make up a significant part of the liability structure. The other interesting pattern is that over the entire sample period, both pre-crisis and throughout the crisis, the leverage ratios remained fairly constant. 
Figure 7: Economic Capital Deficiency (as \% of Book Value of Assets) Full Sample

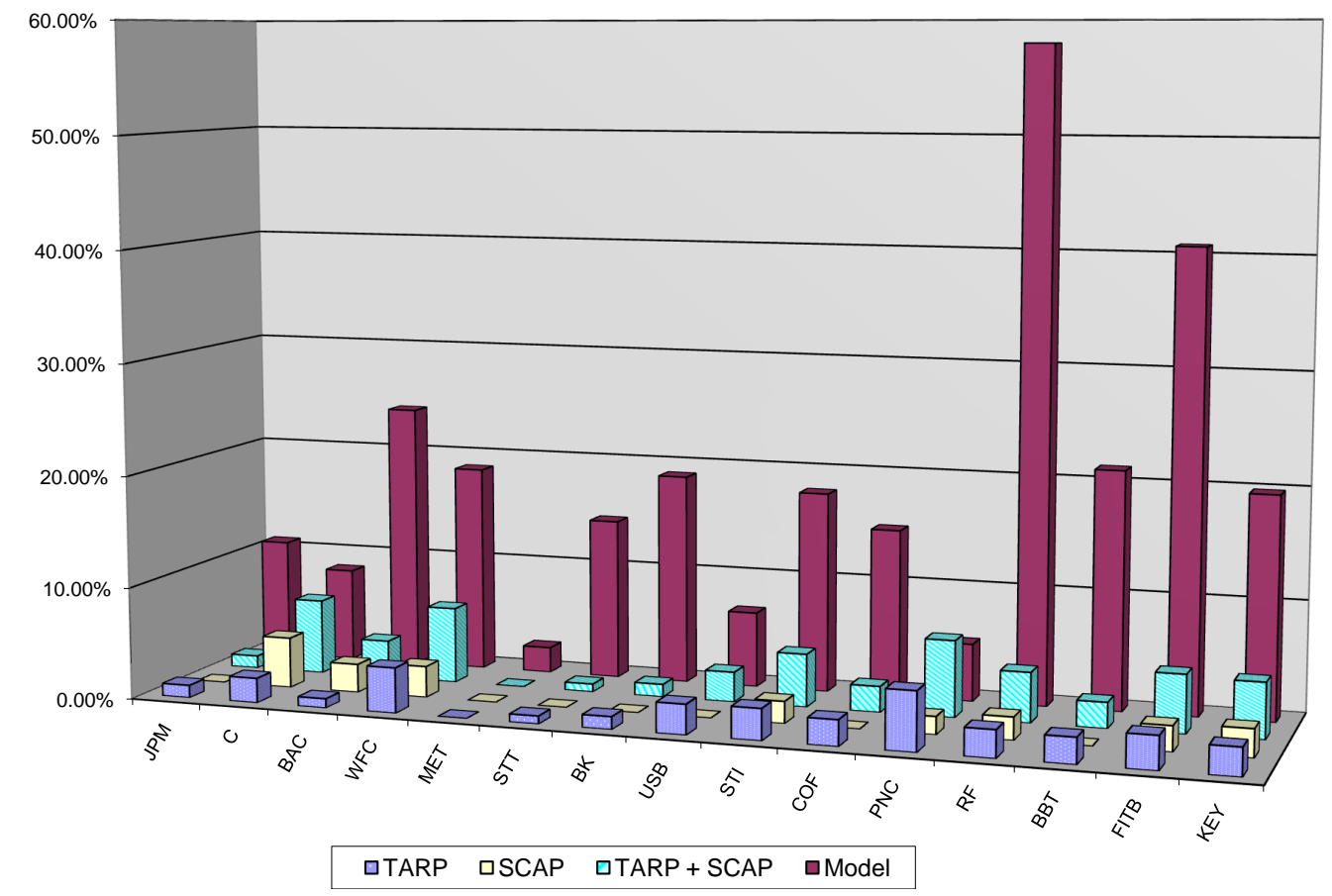


Figure 8: Economic Capital Deficiency (as \% of Book Value of Assets) Restricted Sample

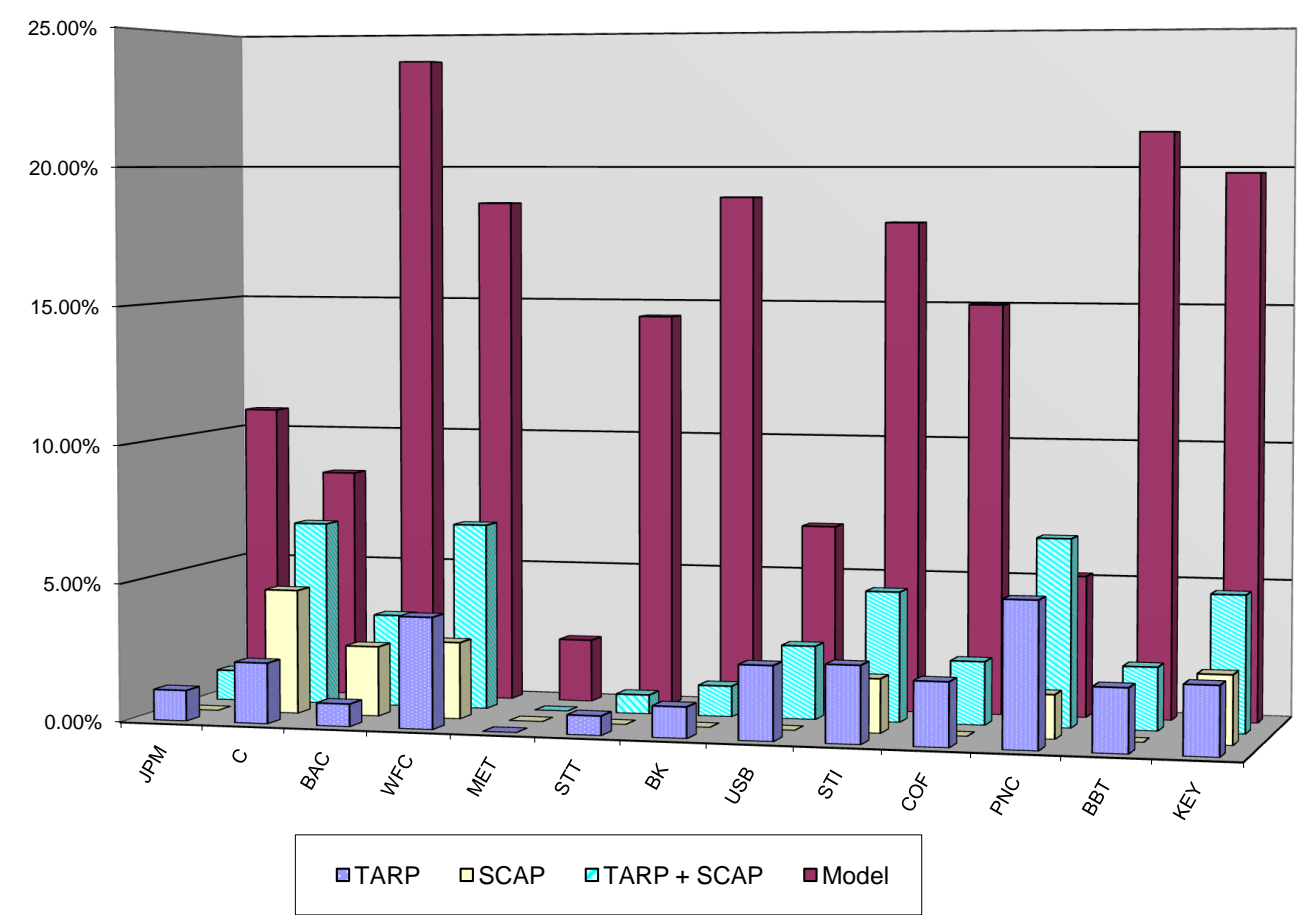


Table 1: Sample Bank Holding Companies

\begin{tabular}{|l|r|r|r|}
\hline BHC Name & Average of Assets(\$000) & RSSD & PERMCO \\
\hline \hline Citigroup, Inc. & $1,876,114,000.00$ & 1951350 & 20483 \\
\hline Bank of America Corporation & $1,575,188,544.25$ & 1073757 & 3151 \\
\hline JPMorgan Chase & $1,571,915,250.00$ & 1039502 & 20436 \\
\hline Wells Fargo & $712,204,500.00$ & 1120754 & 21305 \\
\hline MetLife, Inc. & $517,400,453.50$ & 2945824 & 37138 \\
\hline U.S. Bancorp & $233,336,000.00$ & 1119794 & 1645 \\
\hline SunTrust Banks, Inc. & $182,646,586.00$ & 1131787 & 21691 \\
\hline Bank of New York Mellon & $160,275,750.00$ & 3587146 & 20265 \\
\hline PNC Financial Services Group, Inc. & $155,978,908.75$ & 1069778 & 3685 \\
\hline Capital One Financial Corporation & $138,736,129.00$ & 2277860 & 30513 \\
\hline State Street Corporation & $131,237,511.50$ & 1111435 & 4260 \\
\hline Regions Financial Corp & $128,863,667.50$ & 3242838 & 1620 \\
\hline BB\&T Corporation & $128,788,362.50$ & 1074156 & 4163 \\
\hline Fifth Third Bancorp & $109,154,909.50$ & 1070345 & 1741 \\
\hline KeyCorp & $97,426,130.75$ & 1068025 & 2535 \\
\hline
\end{tabular}

Table 1 shows the 15 Bank Holding Companies (BHCs) that are included in the study. Average assets were computed using the year end consolidated asset amount. A detailed description of the sample selection process can be found in Section 4. The most recent $\mathrm{BHC}$ names and RSSD numbers are listed above. 
Table 2: Data Items

\begin{tabular}{|l|l|l|l|}
\hline & Data Item & Source & Code \\
\hline \hline 1 & Non-interest-bearing deposits in domestic offices & BHCDB & BHDM6631 \\
\hline 2 & Interest-bearing deposits in domestic offices & BHCDB & BHDM6636 \\
\hline 3 & Non-interest-bearing deposits in foreign offices & BHCDB & BHFM6631 \\
\hline 4 & Interest-bearing deposits in foreign offices & BHCDB & BHFM6636 \\
\hline 5 & Federal Funds Purchased & BHCDB & BHDMB993 \\
\hline 6 & Repurchase Agreements & BHCDB & BHCKB995 \\
\hline 7 & Commercial Paper & BHCDB & BHCK2309 \\
\hline 8 & Other Borrowed Money with remaining maturity of 1 year or less & BHCDB & BHCK2332 \\
\hline 9 & Subordinated Notes and Debentures & BHCDB & BHCK4062 \\
\hline 10 & Trust Preferred Securities & BHCDB & BHCKC699 \\
\hline 11 & Tier 1 Capital & BHCDB & BHCK8274 \\
\hline 12 & Total Risk-Weighted Assets & BHCDB & BHCKA223 \\
\hline 13 & Stock Price & CRSP & PRC \\
\hline 14 & Shares Outstanding & CRSP & SHROUT \\
\hline 15 & Total Assets & Compustat & ATQ \\
\hline 16 & Total Liabilities & Compustat & LTQ \\
\hline
\end{tabular}

Table 2 shows the data items that were collected and used in the empirical analysis. A discussion regarding how these data items were used to construct the relevant variables can be found in Section 4. The main data sources are the Bank Holding Company Database (BHCDB), CRSP, and Compustat. The column labeled Code gives the corresponding data item code in the respective database. 